\title{
25 Research Square \\ Study on landscape quality evaluation of Urban Forest Park: a case from China
}

\section{Tao Sun}

Nanjing University of Aeronautics and Astronautics College of Economics and Management https://orcid.org/0000-0003-3121-2340

Xiuyan Han ( $\nabla$ njuptxiuyanhan@163.com )

https://orcid.org/0000-0003-2088-2066

\section{Tianyi Cao}

Dalian University of Technology

\section{Research}

Keywords: Landscape quality, urban forest parks, spatial niche suitability model, comprehensive assessment, Nanjing Zijinshan National Forest Park

Posted Date: December 10th, 2019

DOI: https://doi.org/10.21203/rs.2.18460/v1

License: (c) (i) This work is licensed under a Creative Commons Attribution 4.0 International License. Read Full License 


\title{
Study on landscape quality Assessment of Urban Forest Parks: a case from China
}

\author{
Tao Sun ${ }^{1}$, Xiuyan $\mathrm{Han}^{1 *}$, and Tianyi Cao ${ }^{2}$ \\ ${ }^{1}$ College of Economics and Management, Nanjing University of Aeronautics and Astronautics, Nanjing Jiangsu 211106 China; \\ 2 School of Economics and Management of Dalian University of Technology, Dalian, Liaoning 116024 China; E-mail:
}

\begin{abstract}
Background: Nanjing Zijinshan National Forest Park is a 5A level scenic spot approved by the Chinese government and a world-famous tourist attraction. Due to the decrease of forest coverage and the assessment pollution caused by the large scale of tourism, the requirements of landscape quality assessment of urban forest parks are put forward.
\end{abstract}

Results: In order to explore assessment methods of landscape quality (LQ) of Urban Forest Parks, based on the literature review and current situation analysis, this paper selected 26 assessment indexes of five categories to construct the index system of comprehensive landscape quality assessment of urban forest parks. In view of requirements of landscape quality assessment of urban forest parks, niche suitability model (NSM) was introduced. On the basis of analysis and improvement, spatial niche suitability model (SNSM) was constructed combining absolute niche suitability model and relative niche suitability model by using weighted average method. Then, the application test of SNSM was carried out taking Nanjing Zijinshan National Forest Park as the research target.

Conclusions: The assessment results show that the landscape quality of Nanjing Zijinshan National Forest Park showed a slow upward trend from 2000 to 2018, and was at the lower middle level in 5A scenic area; at the same time, due to buildings increasing and environmental pollution, forest landscape quality showed a slow downward trend. The assessment results of spatial niche suitability model are in line with the actual situation of landscape quality of Nanjing Zijinshan National Forest Park, and provide an effective quantitative analysis method for urban forest parks to strengthen landscape quality management and prevent landscape quality risks.

Keywords: Landscape quality; urban forest parks; spatial niche suitability model; comprehensive assessment; Nanjing Zijinshan National Forest Park

Corresponding author Xiuyan Han, E-mail: njuptxiuyanhan@163.com； Tel.: +86-139-1301-6016 


\section{Background}

With the rapid development of China's economy, urban forest parks has gradually emerged and developed rapidly. As the "green lung" of the city, urban forest parks plays an important role in regulating the air quality of the city, cultivating the residents' life sentiment and improving the life quality [1]. Urban Forest Parks are located in the city, and connected with the living area of residents. It is an ecological service system, and its environmental conditions directly affect the quality of life and physical and mental health of residents. A good urban forest parks can absorb some $\mathrm{CO}_{2}$ in cities, release a lot of oxygen, and purify the air in the city; a beautiful urban forest park, whose landscape can bring people beautiful enjoyment, becomes an important place for residents' morning exercise, leisure, tourism and other activities. In the process of appreciating the beautiful landscape of the forest parks, people feel happy, release pressure and enjoy high Oxygen air, etc. Therefore, landscape quality (LQ) of Urban Forest Parks (UFP) are significant resource to improve the life quality of residents [2]. On the contrary, if urban forest parks are negatively affected by natural disasters or people's activities [3], they will produce environmental pollution, ecological environment damage and landscape quality degradation, will not only not bring the enjoyment of beauty to the residents, but also affect the living environment, health and even life of the residents [4].According to the latest research results of Urban Forest Parks, due to the impact of excessive carbon emissions in the process of economic development and the impact of excessive tourists entering scenic spots and generating a lot of garbage, the landscape quality has begun to suffer some influence, resulting in a certain degree of environmental pollution [5]. In this case, the landscape quality assessment (LQA) of urban forest parks has been raised and gradually become an important issue to be solved [6]. As an important regulatory means, landscape quality assessment of urban forest parks plays an critical role in strengthening the overall planning of forest parks, finding out the problems in the process of construction and management in time, formulating the environmental protection policies of scenic spots, controlling the scale of tourists entering scenic spots and improving the landscape quality of the forest parks [7]. 
Urban Forest Parks are developed on the basis of forest resources. Without forest, there will be no forest park, let alone urban forest parks. Therefore, forest landscape assessment, forest park landscape assessment and urban forest park landscape assessment have basically the same assessment theory and assessment requirements, but there are differences in assessment content and assessment methods. Landscape quality assessment of urban forest parks includes assessment content of the landscape quality of forest parks, and that of non-forest parks, which is also the feature of the difference between landscape quality assessment of urban forest parks and the other two forms of landscape quality assessment [8-9]. For a long time, the academic research on landscape quality assessment and its application of urban forest parks has focused on the theory of landscape and landscape quality, quality assessment of forest landscape, quality assessment of forest park landscape and the quality assessment of urban forest park landscape. These research contents have a progressive relationship from the theoretical research of forest park landscape to the urban forest gradually Landscape quality assessment of the park [10]. The academic research on the theory of landscape and landscape quality is relatively broad, involving many aspects. Main purpose of the research is to lay a theoretical foundation for landscape quality assessment. In China researches on the theory of urban forest park landscape quality is relatively divergent, involving all relevant content, combined with the requirements of landscape quality assessment, from the basic content to expand the research gradually. Some scholars pay more attention to the analysis of the influencing factors of the landscape quality of urban forest parks. Through factor analysis, research direction and important contents of the forest landscape quality assessment are clarified, so as to select the relevant indicators of the landscape quality assessment according to the importance of influencing factors [11]; some scholars attach importance to the study of forest landscape and diversity of landscape quality. They believe that the diversity of landscape quality determines the diversity of forest landscape quality assessment indicators, and advocate using different indicators to reflect the scope and degree of diversity, so as to improve the effect of forest park landscape quality assessment [12]; some scholars attach great importance to the study of forest landscape policy, and believe that forest policy and forest quality protection policy are important guarantee to improve the quality of forest landscape. 
Therefore, we should strengthen the study of forest landscape protection and compensation, the social ecosystem of forest landscape and the potential decline of forest landscape quality [13].

Forest landscape quality assessment is a connotation and rich concept, which can be divided into narrow and broad sense. In a narrow sense, forest landscape quality assessment refers to the comprehensive assessment of forest landscape quality status and the behavior and process of determining its landscape quality level. In this form, forest mainly refers to the original forest or artificial forestation; in a broad sense, forest landscape quality assessment refers to the comprehensive assessment of forest resources in various forms and the landscape quality status of specific areas, the behavior and process of determining its quality level, Including: landscape quality assessment of primitive forest areas, artificial forest areas, forest parks, urban forest parks and other contents [14-15]. With the development of economy, the forest park is a park constructed by the government and enterprises to adapt to the needs of residents' leisure and tourism, using the existing forestry or land advantages to develop a large area of artificial forest or natural forest as the main body [16]. China's forest parks have two basic purposes, public welfare and commercial, or a combination of the two. Commercial forest parks collect tickets and engage in business activities for the purpose of profit; public welfare forest parks are open free of charge for the purpose of leisure. No matter which form of the forest park, it is inseparable from the important means of landscape quality assessment. Therefore, development of forest parks promotes the continuous upgrading of landscape quality assessment research [17].With gradual improvement of residents' living quality; residents' requirements for living environment are also growing. In order to meet the needs of residents for environment, leisure, exercise and other aspects, urban forest park is gradually born and rapidly developed. The scale and reputation of urban forest parks has gradually become a crucial factor of urban competitiveness and attraction [18].Traditional assessment methods, such as expert scoring method, entropy weight method, analytic hierarchy process, fuzzy assessment method, extension assessment method, etc., are often used in landscape quality assessment of urban forest park landscape quality in academic circles. These assessment methods have their own advantages and disadvantages, and have different applicable environments. Some scholars also choose 
some special assessment methods, such as landscape quality index method [19], psychophysics Methods, traditional niche model, etc. [20]. Landscape quality assessment methods of urban forest parks have attracted the attention of scholars and gradually become a crucial problem to be solved [21].

From the above literature review, it can be seen that scholars in China and abroad study management and improvement of urban forest parks landscape quality from different aspects, and assessment methods and application of urban forest park landscape quality is an important content. There are still some unsolved problems in the research of the existing methods and their application of forest park landscape quality assessment. The existing problems in the selection of assessment indicators include: most studies often ignore the vulnerability of forest in the assessment of landscape quality of urban forest parks, and forest quality in urban forest parks faces a worse environment than the original forest, which should be considered in landscape quality assessment of urban forest parks [22-23]. From aesthetic point of view, landscape quality of urban forest parks should have the assessment indexes of landscape coordination. Without important landscape resources, the quality of urban forest parks will be greatly reduced [24]. Urban forest parks are different from forests and a forest parks in that it has a deep cultural connotation. Lack of cultural attractions in urban forest parks makes the quality of park landscape defective. In order to meet the needs of citizens in leisure, exercise and entertainment, urban forest parks require high-quality botanical garden, characteristic garden, high-quality grade leisure lawn area, etc. [25-26]. In addition, environmental protection needs to be strengthened for the energy consumption and pollution emission in the rapid economic development of China, and carbon emission generated by the increase of tourism scale, the increase of garbage and the damage of tourists to the scenic area resources [27-28]. Therefore, the indicators of environmental pollution and its protection should be reflected in the landscape quality assessment indexes of urban forest parks [29]. In the process of model construction, the main problem is the lack of innovation and effectiveness of the selected model. In the traditional landscape quality assessment process of urban forest parks, qualitative assessment methods and simple assessment models are often used. Because the number of assessment indexes selected is relatively small and unreasonable, more importantly, the 
assessment model is too simple to solve the problem of landscape quality assessment of urban forest parks which is a complex problem, resulting in effectiveness reduction of landscape quality assessment in the process of application [30]. Therefore, according to the requirements and actual situation of landscape quality assessment of Nanjing Zijinshan National Forest Park, the purpose of this paper is to solve the above problems and explore effective methods of landscape quality assessment of Nanjing Zijinshan National Forest Park.

\section{Methods}

\subsection{Research object and data source}

Nanjing Zijinshan National Forest Park is named after Zijinshan, which is located in Xuanwu District, Nanjing. It is the first large-scale urban forest park rated as "National Forest Park" in China, the first batch of national 5A tourist attractions, and also the demonstration site of Chinese ecological culture. The forest atmosphere in the park is rich, the forest appearance is neat, and the biodiversity is well preserved [31].In Nanjing Zijinshan National Forest Park, there are 2 national key cultural relics protection units, 9 provincial cultural relics protection units and 33 municipal cultural relics protection units, more than 200 natural and cultural landscapes, as well as famous scientific research sites and landscapes such as Zijinshan Observatory and Zhongshan Botanical Garden, which is known as "the first cultural mountain in China". Nanjing Zijinshan National Forest Park is a famous tourist attraction. There are many scenic spots in the park, with Zhongshan cemetery as the center, Ming Xiaoling and Linggu Temple as the support. There are more than 200 kinds of scenic spots and 84 scenic spots available. Among them, there are 1 world cultural heritage site, 15 national key cultural relic protection sites, and 31 cultural relic protection sites in Jiangsu Province and municipal level. The scenic spot is divided into five parts: Ming Xiaoling scenic spot, Zhongshan Mausoleum scenic spot, Linggu scenic spot, toutuoling scenic spot and other scenic spots [32].

Zijinshan Forest Park is located in the center of Nanjing City, adjacent to the famous Xuanwu Lake, forming a beautiful urban landscape with mountains and rivers, which plays an important role in regulating the urban air, 
residents' leisure, tourism and developing tourism industry [33]. There are 1138 species of seed plants in Zijinshan Forest Park, including 499 species of woody plants, 569 species of herbaceous plants and 70 species of lianas. The main vegetation types of Zijinshan are coniferous forest, mixed coniferous and broad-leaved forest, broad-leaved forest, bamboo forest and shrub [34]. Nanjing Zijinshan National Forest Park is located in the mid latitude area, with subtropical monsoon climate, abundant rainfall, four distinct seasons and mild climate [35]. Due to the special terrain and large area of forest vegetation, Zijinshan scenic spot has the characteristics of local microclimate in a large range of climate conditions. Nanjing Zijinshan National Forest Park has 1628.8 hours of annual average sunshine, $19.6{ }^{\circ} \mathrm{C}$ of average temperature, $38.8{ }^{\circ} \mathrm{C}$ of extreme maximum temperature and $-3.7{ }^{\circ} \mathrm{C}$ of extreme minimum temperature, $1530.1 \mathrm{~mm}$ of annual average precipitation, $2371.4 \mathrm{~mm}$ of annual maximum precipitation, $1091 \mathrm{~mm}$ of minimum precipitation and 322 days of frost free period. Abundant light and heat, abundant rainfall and mild climate in the park provide good conditions for the development of agricultural economy [36]. The construction of Nanjing Zijinshan Forest Park started from 1949. It mainly adopts the way of closing the mountain for afforestation and artificial afforestation to make Zijinshan all green. Since 1996, Zhongshan Cemetery Administration Bureau has established Plum Blossom Festival, Guihua Festival, Ming Xiaoling Cultural Festival, Kite Festival, Zijin summer and other activities by taking advantage of the natural and cultural landscape resources in the forest park. In 1997, Zijinshan Plum Blossom Festival was officially named "Nanjing International Plum Blossom Festival of China". In 2008, Guihua festival was listed as a traditional cultural festival brand in Jiangsu Province, July 3, 2003, Xiaoling of Ming Dynasty is listed in the world cultural heritage. In December, Nanjing Zijinshan National Forest Park was rated as "National Forest Park" In March 2004, the comprehensive environmental improvement project of Zhongshan cemetery was launched in an all-round way. The project lasted for four years and invested more than 5 billion yuan. The simultaneous implementation of the project of demolition, construction and conversion of cropland to forest has increased more than $7000 \mathrm{mu}$ of green space, planted more than 500000 trees, and the green coverage rate has reached more than $80 \%$. In 2009 , Zhongshan cemetery was 
named as the first batch of "national ecological and cultural demonstration base" by the government. Since then, Zijinshan National Forest Park has a good reputation in China and abroad [37].

Since May 2018, our research team has organized an investigation team to conduct a one-year field survey in order to achieve an effective assessment of the landscape quality of Nanjing Zijinshan forest park. On the basis of making a thorough investigation plan, the research data collection work is divided into four parts. Firstly, it is consulted the historical data of Zijinshan Mountain, the statistical data of Zhongshan Mausoleum Administration Bureau, the Research Report of relevant departments in Nanjing, the statistical data of Nanjing Tourism Administration, the statistical data of Nanjing Statistics Bureau, and the statistical data of Environmental Protection Bureau. Secondly, by means of network, a comprehensive search of relevant materials was carried out in the electronic library system of Nanjing University of Aeronautics and Astronautics and the electronic databases of Nanjing Library, Jiangsu library and China library. Thirdly, in the major universities and research units in Nanjing, It was consulted and drew on their research reports and their research results on Zijinshan National Forest Park. Finally, we carried out questionnaire surveys on some significant assessment indexes, and got some first-hand information through questionnaire survey, network questionnaire and on-site questionnaire.

\subsection{Construction of assessment index system}

The comprehensive assessment of the landscape quality of Zijinshan National Forest Park runs through the whole process of landscape quality management, which is a critical means to restore and improve the ecological environment of Zijinshan Forest Park and maximize the quality of the landscape [38]. In order to improve the effectiveness of the landscape quality assessment of Zijinshan National Forest Park, on the basis of the current situation analysis, combined with the specific requirements of Zijinshan National Forest Park in the landscape quality assessment, referring to the requirements of rule 2 of the national standard assessment rules (2005) of the assessment and classification of the quality of tourist attractions, this paper selected 26 assessment indexes in total of five categories, namely, forest landscape, botanical garden landscape, mountain-water landscape, culture 
landscape and forest park landscape, to construct the index system of comprehensive landscape quality assessment

of urban forest parks.. See Table 1 for the specific assessment index names and assessment index system.

Table1 Comprehensive assessment index system of landscape quality of urban forest parks

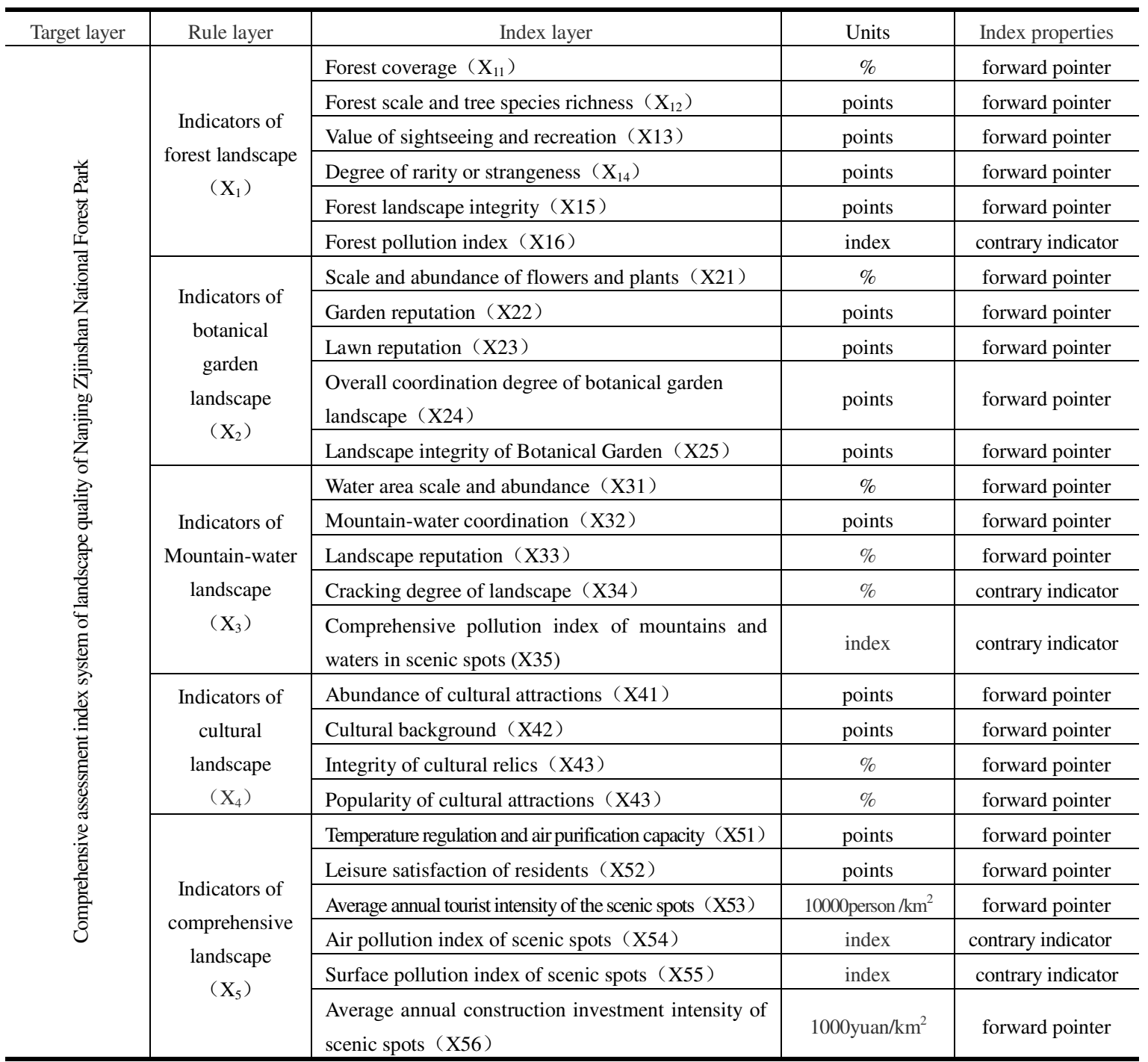

The assessment indexes in Table 1 are selected to construct the index system of landscape quality assessment of

Nanjing Zijinshan National Forest Park. The public characteristics of all urban forest parks are considered in the construction, the latest research results in China and abroad are used for reference, and all regulations and national standards formulated by the regulatory authorities of the Chinese government are also met. In order to facilitate the assessment of Urban Forest Park, the connotation and calculation method of the assessment index are as follows:

(1) Indicators of forest landscape. Six indexes are selected for this category. The meaning of each index and the determination method of assessment value are as follows: (1) forest coverage. It refers to the ratio of the forest 
coverage area to the total area of the park in urban forest parks, reflecting the forest coverage degree; (2) forest scale and tree species richness. Forest scale refers to the total amount of trees in urban forest parks and the size of the floor area. Tree species richness refers to the richness of trees in urban forest parks. The forest scale can be divided into four grades: huge, large, large and medium. The national standards of tree species is $>10$ species (general), $>20$ species (medium), > 30 species (rich), > 40 species (very rich). In the assessment, 2-3 rounds of expert scores are used to determine the final value according to the criteria determined in advance; (3)value of sightseeing and recreation. Sightseeing refers to a kind of appreciative viewing mentality, viewing and appreciation. The basic meaning of recreation is going sightseeing and rest, which can be individual or group activities, including residents' leisure and tourists' tourism. In the assessment, value of sightseeing and recreation is divided into four levels: very high value, high value, general value and small value, and the specific score is determined by experts' scoring; (4) degree of rarity or strangeness. Rarity refers to the existence of precious or rare species. Strangeness is unusual, very rare, amazing species or behavior. In the assessment, the degree of rarity is divided into four states: a large number, a large number, a small number and an individual; the degree of strangeness is divided into four states: unusual, peculiar, prominent and relatively prominent filamentous state, and the assessment value of this index is determined by experts with reference to the scores of standard directors; (5) forest landscape integrity. It means that the forest resources are intact, without damage, pollution or damage, and keep the original shape and structure, etc. the assessment value is determined by expert scoring; (6) forest pollution index. It is an important indicator to reflect the pollution degree. The larger the pollution index value is, the more serious the pollution degree is. $0-50$ is excellent, $51-100$ is good, 101-150 is light pollution, 151-200 is light pollution, 201-250 is medium heavy pollution, 251-300 is medium heavy pollution, and the pollution index is greater than 300 is heavy pollution. In the assessment, the 5A boundary of this index is determined as 150 .

(2) Indicators of botanical garden landscape. Botanical garden is a major feature of urban forest parks. There are 5 indicators in total. Most of the assessment indicators are determined by expert scoring. The following main analysis 
is about the connotation of the indicators. (1) scale and abundance of flowers and plants. The open space of urban forest park is mainly composed of garden, lawn and special resource Park, mainly using the scale and richness of these resources; (2) garden reputation. Reputation refers to the city with beautiful scenery and reputation of scenic spots. The urban forest park is characterized by gardens, for example, "Plum Blossom Mountain" and "Osmanthus Garden" of Nanjing Zijinshan National Forest Park are well-known in the world. During the assessment, the index is divided into four grades: excellent reputation and praise of more than 95 tourists, good reputation and praise of more than 85 tourists, good reputation and praise of more than 75 tourists and a certain reputation and praise of more than 65 tourists; (3) lawn reputation. Besides the function for tourists to enjoy, lawn is also an important place for residents to relax. Meihuashan leisure square of Nanjing Zijinshan National Forest Park enjoys a good reputation in Nanjing. The determination method of lawn reputation index is the same as that of garden reputation; (4) overall coordination degree of botanical garden landscape. Coordination degree refers to the degree of harmony of the target system or the internal elements of the system in the development process. It is a quantitative index reflecting the quality of coordination. During the assessment, the coordination areas are divided into four categories: very coordination, coordination, basic coordination and insufficient coordination; (5) landscape integrity of botanical garden. This index mainly inspects the overall integrity of the botanical garden. Flowers and plants in the botanical garden and other resources are intact, and the shape and structure of the botanical garden are in the original state. It can be divided into four states: very complete, complete, basically complete and incomplete.

(3) Indicators of mountain and water landscape. Five indexes are selected for this kind of index. The meanings of each index are as follows: (1) water area scale and abundance. Water area scale mainly refers to the size of water area and the proportion in the park. Water area abundance refers to the richness of water area, including: mountains and rivers, waterfalls, lakes, streams and other waters. Zijinshan National Forest Park is adjacent to the famous Xuanwu Lake, part water area of which is in the park, and there are dozens of famous lakes such as Zixia lake, Qianhu lake and Baima Lake; (2) mountain-water coordination. This index refers to the coordination degree 
of the landscape resources in the urban forest park. The assessment includes the scale of mountains and waters, the richness of mountains and waters, the overall coordination of mountains and waters, and the coordination of mountains and waters of major scenic spots; (3) landscape reputation. This index assesses the reputation and reputation of mountains and waters in urban forest parks. Zhongshanling and Mingxiaoling in Zijinshan Forest Park are famous all over the world. Xuanwu Lake and Zixialake are also famous. In the assessment, we mainly consider a variety of situations from two aspects of beauty and reputation; (4) cracking degree of landscape. It mainly refers to the degree of aging, damage, defect, pollution and disrepair of landscape, which affects the quality of landscape; (5) comprehensive pollution index of mountains and waters in scenic spots. This index reflects the degree of pollution of mountains and waters in urban forest parks. The meaning and determination method of the index are the same as the previous index of forest pollution.

(4) Indicators of cultural landscape. 4 indexes were selected and the meaning of each index is as follows: abundance of cultural attractions. It evaluates the scale and richness of the cultural sites of urban forest parks, and is classified into: cultural attractions is quite rich, rich and general rich and rich enough four conditions; (2) culture background. It is the breadth and depth of the human spirit achievement, that is, cultural characteristics of the moral ideas and the concept of life that person or group uphold, and also a learning culture and spiritual culture; (3) integrity of cultural relics. It focuses on the main body of cultural relics, appearance, degree of completion of the form, structure, etc., which can be damaged, polluted, and even destroyed. The index determination method is basically the same as that of the previous index; (4) popularity of cultural attractions. It assesses well-known scope and extent of cultural attractions, and is classified into: the world famous, well-known national, province, and city famous.

(5) Indicators of comprehensive landscape. Six indexes are selected and the meanings of each index are as follows: (1) temperature regulation and air purification capacity. These two indexes are related to the forest coverage area, forest density, park structure and geographical location of urban forest parks. In general, the 
capacity of temperature regulation and air purification is positively related to forest conditions; (2) leisure satisfaction of residents. An important role of urban forest parks is to provide places for residents to relax and exercise. Regulated by detailed rules of the national standard assessment rules of the assessment and classification of the quality level of tourist attractions, tourists' opinions are determined according to standards and requirements in the detailed rule 3; (3) average annual tourist intensity of scenic spots. This index refers to the number of tourists per square kilometer in a certain period of time (one year). Within the scope of scenic spots reception capacity, the more the number of tourists, the better it is to reflect the degree of tourists' recognition of the scenic spots. However, the excessive intensity of tourists will cause some damage to the scenic spot. Therefore, it is necessary to strengthen the upper limit control of tourist intensity; (4) air pollution index of scenic spots. The increase of the number of tourists and vehicles in scenic spots will increase carbon emission and other harmful gases. According to measurement results published in the government's environmental situation bulletin, comprehensive assessment of the landscape quality of scenic spots can be realized. The determination method of the assessment index value is the same as before; (5) surface pollution index of scenic spots. Surface pollution of scenic spots is mainly due to the excessive waste discharge caused by excess scale of tourists, which will cause a certain degree of pollution to the ground and the air if it is not disposed in time. The assessment index value is determined using the same method of the above environmental pollution index; (6) average annual construction investment intensity of scenic spots. Investment in scenic spots mainly includes: construction investment, maintenance investment, environmental pollution prevention, control and treatment investment and other related investment. The investment intensity refers to the average investment amount per square kilometer of scenic spots per unit time (one year). The assessment index value is calculated by using the statistical data of the government.

\subsection{Determination of grading standards of landscape quality assessment index and results}

According to China's administrative measures for the assessment of quality grades of tourist attractions (GB/t17775-2003), national standards for the classification and assessment of quality grades of tourist attractions 
(GB/t17775-2003), detailed rules for the assessment of national standards for the assessment and classification of quality grades of tourist attractions (2005) and classification, investigation and assessment of tourist resources (GB/t18972-2003), the latest standards in China and foreign are used for reference based on the comprehensive analysis and in-depth study, the grading standards of landscape assessment index of Nanjing Zijinshan National Forest Park is determined. In the assessment standards, the index lower than the lowest value is recorded as zero, that is, the degree of not reaching the landscape. See Table 2 for the specific grading standards of assessment index.

Table 2 Grading standards of landscape quality assessment indexes of urban forest Parks

\begin{tabular}{|c|c|c|c|c|c|c|}
\hline \multirow{2}{*}{ No. } & \multirow{2}{*}{ index } & \multicolumn{5}{|c|}{ Grading standards of landscape quality assessment index } \\
\hline & & Level I & Level II & Level III & Level IV & Level V \\
\hline 1 & Forest coverage $\left(\mathrm{X}_{11}\right)$ & $80-100$ & $75-80$ & $50-75$ & $40-50$ & $20-40$ \\
\hline 2 & Forest scale and tree species richness $\left(\mathrm{X}_{12}\right)$ & $90-100$ & $85-90$ & $75-85$ & $60-75$ & $50-60$ \\
\hline 3 & Value of sightseeing and recreation (X13) & $90-100$ & $80-90$ & $70-80$ & $60-70$ & $50-60$ \\
\hline 4 & Degree of rarity or strangeness $\left(X_{14}\right)$ & $90-100$ & $80-90$ & $70-80$ & $60-70$ & $50-60$ \\
\hline 5 & Forest landscape integrity (X15) & $90-100$ & $80-90$ & $70-80$ & $60-70$ & $50-60$ \\
\hline 6 & Forest pollution index (X16) & $0-150$ & $150-200$ & $200-250$ & $250-300$ & $>300$ \\
\hline 7 & Scale and abundance of flowers and plants (X21) & $90-100$ & $80-90$ & $70-80$ & $60-70$ & $50-60$ \\
\hline 8 & Garden reputation $(\mathrm{X} 22)$ & $90-100$ & $80-90$ & $70-80$ & $60-70$ & $50-60$ \\
\hline 9 & Lawn reputation $(\mathrm{X} 23)$ & $90-100$ & $80-90$ & $70-80$ & $60-70$ & $50-60$ \\
\hline 10 & $\begin{array}{l}\text { Overall coordination degree of botanical garden } \\
\text { landscape (X24) }\end{array}$ & $90-100$ & $80-90$ & $70-80$ & $60-70$ & $50-60$ \\
\hline 11 & Landscape integrity of Botanical Garden (X25) & $90-100$ & $80-90$ & $70-80$ & $60-70$ & $50-60$ \\
\hline 12 & Water area scale and abundance (X31) & $90-100$ & $80-90$ & $70-80$ & $60-70$ & $50-60$ \\
\hline 13 & Mountain water coordination (X32) & $90-100$ & $80-90$ & $70-80$ & $60-70$ & $50-60$ \\
\hline 14 & Landscape reputation $(\mathrm{X} 33)$ & $90-100$ & $80-90$ & $70-80$ & $60-70$ & $50-60$ \\
\hline 15 & Cracking degree of landscape (X34) & $<2$ & $2-4$ & 4-6 & $6-8$ & $8-10$ \\
\hline 16 & $\begin{array}{l}\text { Comprehensive pollution index of mountains and } \\
\text { waters in scenic spots }(\mathrm{X} 35)\end{array}$ & $0-150$ & $150-200$ & $200-250$ & $250-300$ & $>300$ \\
\hline 17 & Abundance of cultural attractions (X41) & $90-100$ & $80-90$ & $70-80$ & $60-70$ & $50-60$ \\
\hline 18 & Cultural background (X42) & $90-100$ & $80-90$ & $70-80$ & $60-70$ & $50-60$ \\
\hline 19 & Integrity of cultural relics $(X 43)$ & $90-100$ & $80-90$ & $70-80$ & $60-70$ & $50-60$ \\
\hline 20 & Popularity of cultural attractions (X43) & $90-100$ & $80-90$ & $70-80$ & $60-70$ & $50-60$ \\
\hline 21 & Temperature regulation and air purification capacity (X51) & $90-100$ & $80-90$ & $70-80$ & $60-70$ & $50-60$ \\
\hline 22 & Leisure satisfaction of residents (X52) & $90-100$ & $80-90$ & $70-80$ & $60-70$ & $50-60$ \\
\hline 23 & Average annual tourist intensity of scenic spots（X53） & $>20$ & $10-20$ & $5-10$ & $1-5$ & $<1$ \\
\hline 24 & Air pollution index of scenic spots (X54) & $0-150$ & $150-200$ & $200-250$ & $250-300$ & $>300$ \\
\hline 25 & Surface pollution index of scenic spots (X55) & $0-150$ & $150-200$ & $200-250$ & $250-300$ & $>300$ \\
\hline 26 & $\begin{array}{l}\text { Average annual construction investment intensity of } \\
\text { scenic spots (X56) }\end{array}$ & $>4000$ & $3000-4000$ & $2000-3000$ & $1000-2000$ & $<1000$ \\
\hline
\end{tabular}

It can be seen from the Table 2that the assessment indexes are divided into five levels, I-level landscape quality 
is the best, corresponding to 5A scenic area of urban forest parks; V-level landscape quality is the worst, corresponding to 5A scenic area of urban forest parks. In order to assess landscape quality of urban forest parks with multiple indexes, it is necessary to use the comprehensive assessment model to determine landscape quality grade of the assessment object. In this paper, a niche suitability assessment model of is used. The landscape quality of the assessment object is still divided into five grades, and the grading standards of the multi index assessment results are consistent with that of single index assessment results. Referring to the latest research results in China and abroad, taking full account of the actual situation of Nanjing Zijinshan National Forest Park, it is determined the grading standards of landscape quality assessment results. Five-level classification standard is more effective in landscape quality assessment of many urban forest parks, which can determine the landscape quality level of different forest parks. But for Nanjing Zijinshan National Forest Park, it must belong to 5A level scenic spot. It is necessary to refine the 5A level standard, and analyze the change rule of landscape quality of Nanjing Zijinshan Forest Park and solve the existing problems by using the refined level standard of landscape quality assessment results. 5A level standard and detailed new standard are listed in Table 3.

Table 3 Classification standards of landscape quality assessment results of Urban Forest Parks

\begin{tabular}{|c|c|c|c|c|c|}
\hline categries & Level I & Level II & Level III & Level IV & Level V \\
\hline $\mathrm{F}$ & {$[0.90-1.00]$} & {$[0.80-0.90)$} & {$[0.70-0.80)$} & {$[0.50-0.60)$} & {$[0-0.50)$} \\
\hline Landscape quality status & $5 \mathrm{~A}$ & $4 \mathrm{~A}$ & $3 \mathrm{~A}$ & $2 \mathrm{~A}$ & A \\
\hline Refinement category & Level I-1 & Level I-2 & Level I-3 & Level I-4 & Level I-5 \\
\hline $\mathrm{F}^{*}$ & [0.980-1.00] & {$[0.960-0.980)$} & {$[0.940-0.960)$} & {$[0.920-0.940)$} & {$[0.90-0.920)$} \\
\hline 5A landscape quality status & $5 \mathrm{~A}^{++}$ & $5 \mathrm{~A}^{+}$ & $5 \mathrm{~A}$ & $5 \mathrm{~A}^{-}$ & $5 \mathrm{~A}^{--}$ \\
\hline
\end{tabular}

\subsection{Analysis of traditional niche suitability model}

According to the theory of ecological economics, niche refers to the position of a population in an ecosystem in time and space and its functional relationship and function with the related population [39]. It represents the minimum threshold of habitat necessary for the survival of every organism in the ecosystem. Niche modeling (NM) refers to a mathematical model that uses the niche theory and method to determine the quality level of regional Ecological environment by calculating the niche suitability of assessment indexes [40]. Let the ecological factors be expressed 
as: $x_{1}(t) \quad x_{2}(t), \ldots, \quad x_{\mathrm{n}}(t), \quad x_{i}(t) \in I_{i}, \quad I_{i}$ is the variation range of the $\mathrm{i}^{\text {th }}$ ecological factor, it is expressed as: $I_{i}=\left[a_{i}, b_{i}\right],(i=1,2, \cdots, n)$. Then, the domain of ecological factor can be expressed as: $E=I_{1} \times I_{2} \times \cdots \times I_{n}=\prod_{i=1}^{n} I_{i}$. E is a subset of n-dimensional ecological factor $E^{n}$, if the niche function is a non-negative and n-dimensional function: $f\left(X_{i}\right)=f\left(x_{1}(t), x_{2}(t), \ldots, x_{\mathrm{n}}(t)\right)$, then niche $\mathrm{N}$ of this population can be expressed as:

$$
N=\left\{X_{t} \mid f\left(X_{t}\right)>0, X_{\mathrm{t}}=\left(x_{1}(t), x_{2}(t), \cdots, x_{\mathrm{n}}(t)\right)\right\}, \quad N \cap E \neq \Phi
$$

According to niche theory, niche suitability interval is $(0,1)$. The larger the value is, the higher the degree of ecological factors meeting ecological needs is [41]. The optimum value of ecological factors is denoted as: $X_{\alpha}=\left(x_{1}(\alpha) \quad x_{2}(\alpha), \cdots, x_{\mathrm{n}}(\alpha)\right), \quad X_{t} \in E$, then; the niche suitability of ecological factors is denoted as:

$$
F=\phi\left(X_{\alpha}, X_{t}\right), \quad X_{\alpha} \in N, \quad X_{t} \in E
$$

According to the different meanings of $\phi$, niche suitability functions of regional ecological factors have different connotations. According to relevant theories of ecology, the traditional niche model has niche suitability model $\left(\mathrm{F}_{\mathrm{t}}\right)$ and limit factor model $\left(F_{\text {min }-t}\right)$ [42]. The following two basic models of niche assessment are introduced respectively.

(1) Niche suitability model $\left(\mathrm{F}_{\mathrm{t}}\right)$. If the suitability of regional ecological factors in time period $t$ is expressed as $\mathrm{F}_{\mathrm{t}}$, then the corresponding niche suitability model is expressed as follows:

$$
\begin{aligned}
& F_{t}=\frac{1}{n} \sum_{i=1}^{n} \frac{\delta_{\text {min }}+\alpha \times \delta_{\text {max }}}{\delta_{i t}+\alpha \times \delta_{\text {max }}}=\frac{1}{n} \sum_{i=1}^{n} \frac{\min \left\{\left|x_{i}^{\prime}(t)-x_{i}^{\prime}(\alpha)\right|\right\}+\alpha \times \max \left\{\left|x_{i}^{\prime}(t)-x_{i}^{\prime}(\alpha)\right|\right\}}{\mid x_{i}^{\prime}(t)-x_{i}^{\prime}(\alpha)+\alpha \times \max \left\{\left|x_{i}^{\prime}(t)-x_{i}^{\prime}(\alpha)\right|\right\}} \\
& \text { In the type: } \delta_{i t}=\left|x_{i}^{\prime}(t)-x_{i}^{\prime}(\alpha)\right|, \quad(i=1,2, \cdots, n ; \mathrm{t}=1,2, \cdots, \mathrm{m}) \\
& \delta_{\max }=\max \left\{\delta_{i t}\right\}=\left\{\left|x_{i}^{\prime}(t)-x_{i}^{\prime}(\alpha)\right|\right\} \\
& \delta_{\text {min }}=\min \left\{\delta_{i t}\right\}=\left\{\left|x_{i}^{\prime}(t)-x_{i}^{\prime}(\alpha)\right|\right\}
\end{aligned}
$$

$\alpha$ is the model parameter, and the value range of $\alpha$ is : $(0 \leq \alpha \leq 1)$. The calculation results of the model can be adjusted by taking various value of the model parameters according to the changes of environmental conditions, and $\alpha=0.5$ in the average condition.

(2) Limit factor model $\left(\mathrm{F}_{\text {min- } \mathrm{t}}\right)$. If the suitability of ecological factors in time period $t$ is expressed as $: F_{\text {min-t }}$, since 
the minimum value of the ecological factor is taken in the above equation, and the value is limited, it is called the limiting factor model. The specific expression is:

$$
F_{\min -t}=\min \left\{\left(x_{1}^{\prime}(t) / x_{1}^{\prime}(\alpha)\right),\left(x_{2}^{\prime}(t) / x_{2}^{\prime}(\alpha)\right), \cdots,\left(x_{n}^{\prime}(t) / x_{n}^{\prime}(\alpha)\right)\right\}
$$

In the above equation, $x_{i}(t)$ is the measured value of the $\mathrm{i}^{\text {th }}$ ecological factor, and $x_{i}(\alpha)$ is the optimal value of $\mathrm{i}^{\text {th }}$ ecological factor. This model is often used to evaluate the relationship between the most significant limiting factor and its optimal value.

\subsection{Construction of spatial niche suitability model}

According to niche theory and method, the assessment index is expressed as follows: $x_{1}, x_{2}, \cdots, x_{m}$, Considering the time series of each assessment index, the observed values constitute the ecological vector of $\mathrm{m} \times \mathrm{n}$ dimension : $X_{i}=\left(x_{i 1}, x_{i 2}, \cdots, x_{i t}\right),(t=1,2, \cdots, n)$. In order to construct a comprehensive spatial niche suitability assessment model of landscape quality, referring to the research results of [43], the generalized correlation degree in grey theory is introduced to calculate the niche of regional ecological factors, and spatial niche suitability assessment model is constructed using weighted average value of absolute niche suitability model and relative niche suitability model. Absolute niche suitability model is represented by $\mathrm{F}_{\mathrm{t} \alpha}$, relative niche suitability model is represented by $\varepsilon_{\mathrm{t} \alpha}$, and spatial niche suitability model is represented by $\gamma_{\mathrm{t} \alpha}$. In order to reduce the distortion of system data due to the interference of shock wave, a buffer operator is introduced to eliminate the interference [44]. Let D be the average weakening buffer operator (AWBO), and the first-order buffer operator of the actual value of ecological factors can be expressed as:

$$
X_{t} D=\left(x_{1 t}, x_{2 t}, \cdots, x_{m t}\right) \cdot d=\frac{1}{n-i+1}\left(x_{i t}, x_{i+1 t}, \cdots, x_{m t}\right),(i=1,2, \cdots, m ; t=1,2, \cdots, n)
$$

If $\mathrm{D}_{2}$ is the second-order weakening buffer operator, then the second-order buffer sequence of the actual value of ecological factor can be expressed as:

$$
X_{t} D^{2}=\left(x_{1 t}, x_{2 t}, \cdots, x_{m t}\right) \cdot d^{2}=\frac{1}{n-i+1}\left(x_{i t} d+x_{i+1 t} d+\cdots+x_{m t} d\right),(i=1,2, \cdots, m ; t=1,2, \cdots, n)
$$

After the second-order buffer calculation of ecological factors, the data become more stable. In order to 
effectively assess the landscape quality, it is necessary to conduct dimensionless processing on the stationary data of ecological factors, and the value range of the data after processing is between [0,1]. The dimensionless calculation formula is as follows:

$$
\left\{\begin{array}{ll}
x_{i t}^{\prime}=\left(x_{i t} d^{2}\right) /\left(\left(\max x_{i t}\right) d^{2}\right) & (\text { forward pointer }) \\
x_{i t}^{\prime}=1-\left(x_{i t} d^{2}\right) /\left(\left(\max x_{i t}\right) d^{2}\right) & (\text { contrary indicator })
\end{array}, \quad(i=1,2, \cdots, m ; t=1,2, \cdots, n)\right.
$$

In the above equation, $x_{i t}^{\prime}$ represents the dimensionless value of the $\mathrm{i}^{\text {th }}$ factor in time period $\mathrm{t}$, and $\max x_{i t} d^{2}$ represents the maximum value of the $\mathrm{i}^{\text {th }}$ factor in time period $\mathrm{t}$ after the second-order buffering, and the buffering factor $d=1 /(m-i+1)$. If the optimal fitness of the assessment index is $x_{i \alpha}, x_{i \alpha}^{\prime}$ represents the dimensionless value of the optimal fitness of the ith index, then:

$$
\left\{\begin{array}{ll}
x_{i \alpha}^{\prime}=\left(x_{i \alpha} d^{2}\right) /\left(\left(\max x_{i t}\right) d^{2}\right) & (\text { forward pointer) } \\
x_{i \alpha}^{\prime}=1-\left(x_{i \alpha} d^{2}\right) /\left(\left(\max x_{i t}\right) d^{2}\right) & \text { (contrary indicator) }
\end{array} \quad(i=1,2, \cdots, m ; t=1,2, \cdots, n)\right.
$$

On the basis of dimensionless processing, zero image processing is carried out according to the dimensionless results. The value of zero image processing is expressed as follows:

$$
\left\{\begin{array}{l}
x_{i t}^{\prime}(0)=\left(x_{1 t}^{\prime}(0), \quad x_{2 t}^{\prime}(0), \cdots, \quad x_{\mathrm{m} t}^{\prime}(0)\right)=x_{i t}^{\prime}-x_{1 t}^{\prime} \\
x_{i \alpha}^{\prime}(0)=\left(x_{1 \alpha}^{\prime}(0), \quad x_{2 \alpha}^{\prime}(0), \cdots, \quad x_{\mathrm{m} \alpha}^{\prime}(0)\right)=x_{i \alpha}^{\prime}-x_{1 \alpha}^{\prime}
\end{array}\right.
$$

The comprehensive spatial niche suitability assessment model is the weighted average of absolute niche suitability model and relative niche suitability model. In order to build a comprehensive assessment model of spatial niche suitability, it is necessary to build absolute niche suitability $\left(\varepsilon_{t \alpha}\right)$ measurement model first. The specific model expression is as follows:

$$
\begin{aligned}
& \varepsilon_{t \alpha}=\frac{1+\left|S_{\alpha}\right|+\left|S_{t}\right|}{1+\left|S_{\alpha}\right|+\left|S_{t}\right|+\left|S_{\alpha}-S_{t}\right|} \\
& \left\{\begin{array}{l}
S_{t}=\int_{1}^{n}\left(x_{i t}^{\prime}(0)-x_{i 1}^{\prime}(0)\right) d t \\
S_{\alpha}=\int_{1}^{n}\left(x_{i \alpha}^{\prime}(0)-x_{i 1}^{\prime}(0)\right) d t \\
\left|S_{t}\right|=\left|\int_{1}^{n}\left(x_{i t}^{\prime}(0)-x_{i 1}^{\prime}(0)\right) d t\right|=\left|\sum_{k=2}^{n-1} x_{k t}^{\prime}(0)+\frac{1}{2} x_{m t}^{\prime}(0)\right| \\
\left|S_{\alpha}\right|=\left|\int_{1}^{n}\left(x_{i \alpha}^{\prime}(0)-x_{i 1}^{\prime}(0)\right) d t\right|=\left|\sum_{k=2}^{n-1} x_{k \alpha}^{\prime}(0)+\frac{1}{2} x x_{m t}^{\prime}(0)\right| \\
S_{t}-S_{\alpha}=\int_{1}^{n}\left(x_{i t}^{\prime}(0)-x_{i \alpha}^{\prime}(0)\right) d t \\
\left|S_{t}-S_{\alpha}\right|=\left|\sum_{k=2}^{n-1}\left(x_{i \alpha}^{\prime}(0)-x_{i t}^{\prime}(0)\right)+\frac{1}{2}\left(x_{m \alpha}^{\prime}(0)-x_{k t}^{\prime}(0)\right)\right|
\end{array}\right.
\end{aligned}
$$


Then, relative niche suitability model of $\left(\gamma_{t \alpha}\right)$ is determined by using the data weakened buffer and dimensionless. The specific model expression is as follows :

$$
\begin{aligned}
& \gamma_{t \alpha}=\frac{1+\left|S_{\alpha}^{\prime}\right|+\left|S_{t}^{\prime}\right|}{1+\left|S_{\alpha}^{\prime}\right|+\left|S_{t}^{\prime}\right|+\left|S_{\alpha}^{\prime}-S_{t}^{\prime}\right|} \\
& \left\{\begin{array}{l}
S_{t}^{\prime}=\int_{1}^{n}\left(x_{i t}^{\prime \prime}(0)-x_{i 1}^{\prime \prime}(0)\right) d t \\
S_{\alpha}^{\prime}=\int_{1}^{n}\left(x_{i \alpha}^{\prime \prime}(0)-x_{i 1}^{\prime \prime}(0)\right) d t \\
\left|S_{t}^{\prime}\right|=\left|\int_{1}^{n}\left(x_{i t}^{\prime \prime}(0)-x_{i 1}^{\prime \prime}(0)\right) d t\right|=\left|\sum_{k=2}^{m-1} x_{k t}^{\prime \prime}(0)+\frac{1}{2} x_{m t}^{\prime \prime}(0)\right| \\
\left|S_{\alpha}^{\prime}\right|=\left|\int_{1}^{n}\left(x_{i \alpha}^{\prime \prime}(0)-x_{i 1}^{\prime \prime}(0)\right) d t\right|=\left|\sum_{k=2}^{m-1} x_{k \alpha}^{\prime \prime}(0)+\frac{1}{2} x_{m \alpha}^{\prime \prime}(0)\right| \\
S_{t}^{\prime}-S_{\alpha}^{\prime}=\int_{1}^{n}\left(x_{i t}^{\prime \prime}(0)-x_{i \alpha}^{\prime \prime}(0)\right) d t \\
\left|S_{t}^{\prime}-S_{\alpha}^{\prime}\right|=\left|\sum_{k=2}^{n-1}\left(x_{k \alpha}^{\prime \prime}(0)-x_{k t}^{\prime \prime}(0)\right)+\frac{1}{2}\left(x_{m \alpha}^{\prime \prime}(0)-x_{k t}^{\prime \prime}(0)\right)\right|
\end{array}\right.
\end{aligned}
$$

Type $: x_{i t}^{\prime \prime}(0)=\left(x_{1 t}^{\prime \prime}(0), x_{2 t}^{\prime \prime}(0), \cdots, x_{m t}^{\prime \prime}(0)\right)=\left(x_{m t}^{\prime}\right) /\left(x_{1 t}^{\prime}\right)-1, x_{i \alpha}^{\prime \prime}(0)=\left(x_{1 \alpha}^{\prime \prime}(0), x_{2 \alpha}^{\prime \prime}(0), \cdots, x_{m \alpha}^{\prime \prime}(0)\right)=\left(x_{m \alpha}^{\prime}\right) /\left(x_{1 \alpha}^{\prime}\right)-1$. If Ft $\alpha$ is used to represent the comprehensive assessment model of spatial niche suitability, then :

$$
F_{t \alpha}=\theta \varepsilon_{t \alpha}+(1-\theta) \gamma_{t \alpha}
$$

Where, $\theta(0 \leq \theta \leq 1)$ is the weighting coefficient, and considering that the importance of the absolute niche suitability and the relative niche suitability are the same, the value of $\theta$ is 0.5 . When the value is less than 0.5 and tends to 0 , the value of the comprehensive niche suitability tends to the relative niche suitability. When the value of $\theta$ is greater than 0.5 and tends to 1 , the value of comprehensive niche suitability tends to that of absolute niche suitability.

\section{Results}

\subsection{Collection of research data}

In order to study the effectiveness of spatial niche suitability assessment model of landscape quality of urban forest parks, Nanjing Zijinshan National Forest Park was selected as the research object. Landscape quality assessment of Nanjing Zijinshan National Forest Park is a very complex research subject, involving many influences. Moreover, landscape quality of scenic spots cannot be effectively evaluated only by using economic and technical indexes, and the national standards for landscape quality assessment of scenic spots also adopt a 
comprehensive scoring method. Therefore, the study of this paper combined economic and technical indexes with comprehensive scoring ones. Some single and crucial indexes were selected to calculate assessment indicators, and other indexes were selected with statistical results from the state and Nanjing Zhongshan Mausoleum Administration Bureau, such as forest coverage, environmental pollution index, and etc. There were two kinds of scoring indexes, one kind got preliminary survey results through questionnaire survey, such as leisure satisfaction, rare or strange degree, etc.; the other kind relied solely on expert scoring or conducted expert scoring demonstration on the questionnaire survey results. Through more than one year of investigation and research, the basic research data of landscape quality assessment of Nanjing Zijinshan National Forest Park were obtained. The content and changing trend of the basic research data are shown in Table 4.

Table 4 Data collection of comprehensive assessment indexes of LQ of Nanjing Zijinshan National Forest Park

\begin{tabular}{|c|c|c|c|c|c|c|c|c|c|c|}
\hline Criterion level & Index level & 2010 & 2011 & 2012 & 2013 & 2014 & 2015 & 2016 & 2017 & 2018 \\
\hline \multirow{6}{*}{$\begin{array}{l}\text { Indicators } \\
\text { offorest } \\
\text { landscape } \\
\quad\left(\mathrm{X}_{1}\right)\end{array}$} & $\mathrm{X}_{11}$ & 81.34 & 80.56 & 80.05 & 78.48 & 75.28 & 73.27 & 72.48 & 71.68 & 70.20 \\
\hline & $\mathrm{X}_{12}$ & 93.23 & 93.78 & 94.06 & 93.89 & 94.45 & 94.18 & 94.38 & 95.37 & 96.26 \\
\hline & $\mathrm{X}_{13}$ & 94.38 & 95.01 & 95.37 & 96.37 & 96.86 & 97.06 & 97.27 & 98.18 & 98.38 \\
\hline & $\mathrm{X}_{14}$ & 93.28 & 92.69 & 92.38 & 93.14 & 93.76 & 93.03 & 92.85 & 92.65 & 92.38 \\
\hline & $X_{15}$ & 94.57 & 94.27 & 95.27 & 95.06 & 95.42 & 95.86 & 96.08 & 96.17 & 96.38 \\
\hline & $X_{16}$ & 132.69 & 135.48 & 143.49 & 149.39 & 150.28 & 151.38 & 152.39 & 154.32 & 156.69 \\
\hline \multirow{5}{*}{$\begin{array}{c}\text { Indicators } \\
\text { ofbotanical } \\
\text { garden } \\
\text { landscape } \\
\left(\mathrm{X}_{2}\right) \\
\end{array}$} & $X_{21}$ & 94.89 & 95.25 & 95.01 & 95.47 & 95.86 & 96.07 & 96.85 & 97.15 & 97.57 \\
\hline & $\mathrm{X}_{22}$ & 88.38 & 89.85 & 90.37 & 91.29 & 92.38 & 92.87 & 93.29 & 94.09 & 95.13 \\
\hline & $X_{23}$ & 90.28 & 90.78 & 91.37 & 91.89 & 91.67 & 92.37 & 92.58 & 92.89 & 93.29 \\
\hline & $\mathrm{X}_{24}$ & 91.38 & 91.67 & 91.89 & 92.11 & 92.49 & 92.68 & 92.88 & 93.05 & 92.89 \\
\hline & $X_{25}$ & 90.38 & 91.06 & 91.74 & 92.31 & 92.89 & 93.48 & 94.28 & 95.08 & 95.69 \\
\hline \multirow{5}{*}{$\begin{array}{c}\text { Indicators of } \\
\text { Mountain and } \\
\text { water } \\
\text { landscape } \\
\left(\mathrm{X}_{3}\right) \\
\end{array}$} & $X_{31}$ & 91.01 & 91.48 & 91.79 & 91.98 & 92.16 & 92.39 & 92.48 & 92.57 & 92.87 \\
\hline & $\mathrm{X}_{32}$ & 92.02 & 92.31 & 92.46 & 92.41 & 92.62 & 92.78 & 92.89 & 93.07 & 93.28 \\
\hline & $X_{33}$ & 92.38 & 92.84 & 93.48 & 93.79 & 94.45 & 94.75 & 95.47 & 95.82 & 96.13 \\
\hline & $\mathrm{X}_{34}$ & 1.37 & 1.41 & 1.46 & 1.42 & 1.38 & 1.34 & 1.31 & 1.28 & 1.21 \\
\hline & $X_{35}$ & 150.31 & 152.34 & 154.28 & 155.28 & 156.37 & 158.29 & 161.35 & 163.28 & 158.05 \\
\hline \multirow{4}{*}{$\begin{array}{c}\text { Indicators of } \\
\text { cultural } \\
\text { landscape } \\
\left(\mathrm{X}_{4}\right) \\
\end{array}$} & $\mathrm{X}_{41}$ & 91.38 & 91.29 & 91.56 & 91.51 & 91.69 & 91.78 & 91.83 & 92.06 & 92.16 \\
\hline & $\mathrm{X}_{42}$ & 91.37 & 92.17 & 92.57 & 93.33 & 94.21 & 94.34 & 95.05 & 95.35 & 95.76 \\
\hline & $\mathrm{X}_{43}$ & 95.06 & 95.33 & 95.42 & 95.64 & 95.48 & 95.61 & 95.58 & 95.87 & 95.76 \\
\hline & $X_{43}$ & 91.26 & 91.77 & 92.35 & 93.15 & 93.86 & 94.21 & 94.77 & 95.18 & 95.66 \\
\hline \multirow{6}{*}{$\begin{array}{l}\text { Indicators of } \\
\text { comprehensiv } \\
\text { e landscape } \\
\left(\mathrm{X}_{5}\right)\end{array}$} & $\mathrm{X}_{51}$ & 95.54 & 95.11 & 95.07 & 94.89 & 94.58 & 94.75 & 94.27 & 94.03 & 93.79 \\
\hline & $\mathrm{X}_{52}$ & 98.78 & 98.76 & 97.88 & 97.16 & 96.58 & 95.38 & 94.37 & 93.39 & 92.68 \\
\hline & $\mathrm{X}_{53}$ & 21.25 & 24.38 & 26.29 & 26.89 & 27.42 & 28.13 & 29.22 & 30.27 & 35.28 \\
\hline & $\mathrm{X}_{54}$ & 121.28 & 128.37 & 130.28 & 130.79 & 132.26 & 135.38 & 138.69 & 143.28 & 151.39 \\
\hline & $\mathrm{X}_{55}$ & 141.26 & 141.67 & 142.48 & 144.48 & 145.28 & 148.35 & 151.39 & 156.39 & 161.39 \\
\hline & $\mathrm{X}_{56}$ & 4152 & 4564 & 4632 & 4827 & 5116 & 5335 & 5543 & 5654 & 5856 \\
\hline
\end{tabular}

Source: according to the statistical report of Zhongshan Cemetery Administration, the statistical report of Nanjing culture and Tourism Administration, questionnaire survey data and expert survey data. 


\subsection{Technical treatment of assessment indexes}

Technical treatment of the assessment indexes includes second-order buffer processing and dimensionless processing, which is the basic work of landscape quality assessment of Nanjing Zijinshan National Forest Park.

According to the research design, the following contents are analyzed and explained.

\subsubsection{Second-order buffer calculation of assessment index}

For the basic research data in Table 4, the second-order buffer correction formula (5) and (6) of the assessment index are used for calculation to eliminate the large fluctuations in the original data, make the data more stable, and improve the effectiveness of the assessment results. See Table 5 for the specific results of the second-order buffer calculation of the assessment indexes.

Table 5 Second-order buffer processing results of LQ assessment indexes of Nanjing Zijinshan National Forest Park

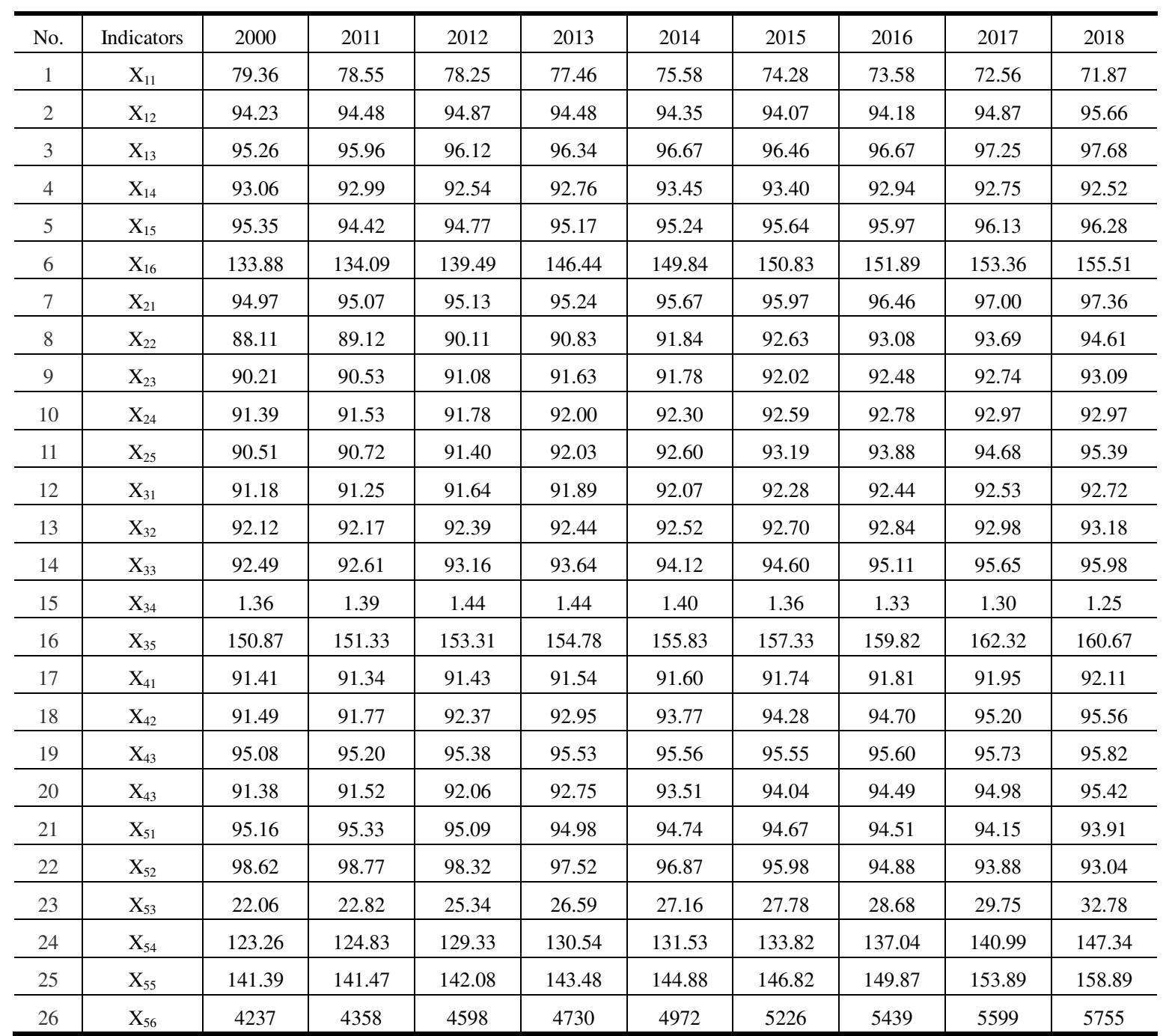


3.2.2 Dimensionless processing of assessment indexes

Formula (7) and (8) are used for dimensionless calculation of the basic data processed by second-order buffer processing. In the process of normalization, the maximum and minimum values of assessment indexes are used for calculation. See Table 6 for the calculation results.

Table 6 Dimensionless processing results of LQ assessment indexes of Nanjing Zijinshan National Forest Park

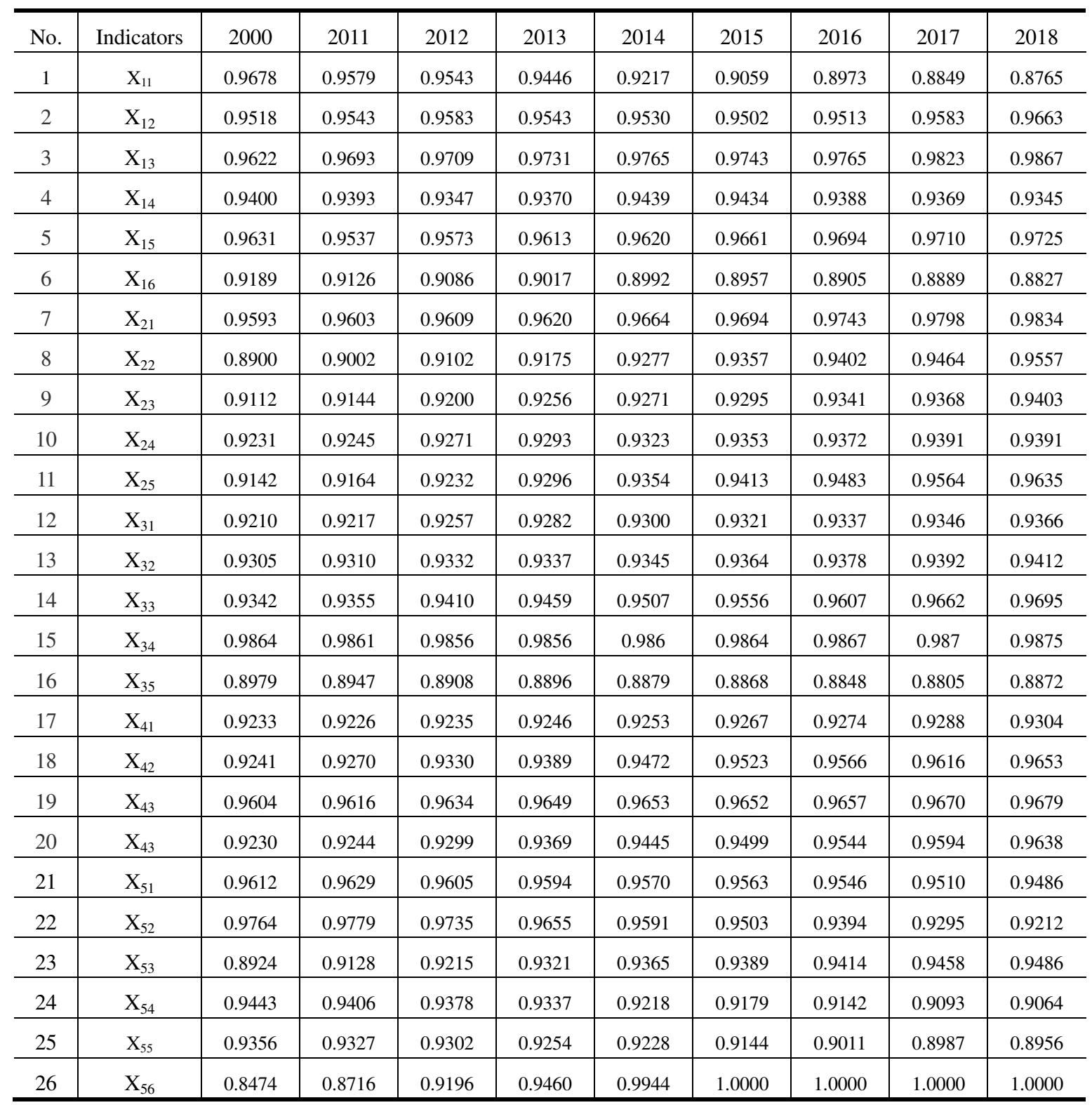

\subsection{Application of comprehensive niche suitability assessment models}

3.3.1Comprehensive assessment of landscape quality of criterion layer

The comprehensive assessment of the landscape quality of Nanjing Zijinshan National Forest Park is divided 
into two levels: criterion layer and target layer. The comprehensive assessment of the landscape quality of criterion layer takes the forest landscape, botanical garden landscape, mountain-water landscape, cultural landscape and scenic area comprehensive landscape of Nanjing Zijinshan National Forest Park as the assessment object, and uses the above models (10) - (13) to calculate absolute niche suitability, relative niche suitability and comprehensive niche suitability of the assessment object respectively. As calculation of niche assessment indicators is influenced much by experts' subjective assessment, the model parameters of balance calculation results are used to reduce the error in the model. In order to reflect the willingness of experts, calculation results of niche suitability should tend to experts' assessment results. Therefore, according to comprehensive analysis, $\alpha$ is determined to be 0.65 , and the specific calculation results of the criterion layer are shown in Table 7.

Table 7 Landscape quality assessment results of the criterion layer of Nanjing Zijinshan National Forest Park

\begin{tabular}{|c|c|c|c|c|c|c|c|c|c|c|}
\hline $\begin{array}{c}\text { Assessment } \\
\text { method }\end{array}$ & indicators & 2000 & 2011 & 2012 & 2013 & 2014 & 2015 & 2016 & 2017 & 2018 \\
\hline \multirow{5}{*}{$\varepsilon_{t \alpha}$} & $X_{I}$ & 0.96023 & 0.9552 & 0.9576 & 0.9488 & 0.9486 & 0.9421 & 0.9418 & 0.9394 & 0.9372 \\
\hline & $\mathrm{X}_{2}$ & 0.9235 & 0.9322 & 0.9381 & 0.9384 & 0.9416 & 0.9468 & 0.9531 & 0.9579 & 0.9591 \\
\hline & $\mathrm{X}_{3}$ & 0.9382 & 0.9389 & 0.9403 & 0.9412 & 0.9431 & 0.9439 & 0.9465 & 0.9455 & 0.9505 \\
\hline & $\mathrm{X}_{4}$ & 0.9337 & 0.9354 & 0.9345 & 0.9421 & 0.9462 & 0.9487 & 0.9526 & 0.9552 & 0.9571 \\
\hline & $\mathrm{X}_{5}$ & 0.9281 & 0.9328 & 0.9395 & 0.9432 & 0.9504 & 0.9484 & 0.9475 & 0.9438 & 0.9408 \\
\hline \multirow{5}{*}{$\gamma_{t \alpha}$} & $\mathrm{X}_{1}$ & 0.9327 & 0.9343 & 0.9285 & 0.9388 & 0.9317 & 0.9341 & 0.9289 & 0.9328 & 0.9352 \\
\hline & $\mathrm{X}_{2}$ & 0.9124 & 0.9065 & 0.9101 & 0.9224 & 0.9307 & 0.9337 & 0.9351 & 0.9402 & 0.9514 \\
\hline & $X_{3}$ & 0.9262 & 0.9243 & 0.9260 & 0.9281 & 0.9280 & 0.9313 & 0.9299 & 0.9341 & 0.9331 \\
\hline & $\mathrm{X}_{4}$ & 0.9308 & 0.9311 & 0.9431 & 0.9398 & 0.9445 & 0.9481 & 0.9480 & 0.9523 & 0.9565 \\
\hline & $\mathrm{X}_{5}$ & 0.9227 & 0.9337 & 0.9424 & 0.9446 & 0.9453 & 0.9424 & 0.9312 & 0.9304 & 0.9291 \\
\hline \multirow{5}{*}{$F_{t \alpha}$} & $\mathrm{X}_{1}$ & 0.9506 & 0.9479 & 0.9474 & 0.9453 & 0.9427 & 0.9393 & 0.9373 & 0.9371 & 0.9365 \\
\hline & $\mathrm{X}_{2}$ & 0.9196 & 0.9232 & 0.9283 & 0.9328 & 0.9378 & 0.9422 & 0.9468 & 0.9517 & 0.9564 \\
\hline & $\mathrm{X}_{3}$ & 0.9340 & 0.9338 & 0.9353 & 0.9366 & 0.9378 & 0.9395 & 0.9407 & 0.9415 & 0.9444 \\
\hline & $\mathrm{X}_{4}$ & 0.9327 & 0.9339 & 0.9375 & 0.9413 & 0.9456 & 0.9485 & 0.9510 & 0.9542 & 0.9569 \\
\hline & $\mathrm{X}_{5}$ & 0.9262 & 0.9331 & 0.9405 & 0.9437 & 0.9486 & 0.9463 & 0.9418 & 0.9391 & 0.9367 \\
\hline
\end{tabular}

According to the above calculation results of Spatial Niche suitability, combined with 5A landscape quality grading standards of Urban Forest Park, the comprehensive assessment results of landscape quality of criterion layer are determined as follows: 
Table 8 Landscape quality levels of criterion layer of Nanjing Zijinshan National Forest Park

\begin{tabular}{c|c|c|c|c|c|c|c|c|c}
\hline name of index & 2000 & 2011 & 2012 & 2013 & 2014 & 2015 & 2016 & 2017 & 2018 \\
\hline $\mathrm{X}_{1}$ & $5 \mathrm{~A}$ & $5 \mathrm{~A}$ & $5 \mathrm{~A}$ & $5 \mathrm{~A}$ & $5 \mathrm{~A}$ & $5 \mathrm{~A}^{-}$ & $5 \mathrm{~A}^{-}$ & $5 \mathrm{~A}^{-}$ & $5 \mathrm{~A}^{-}$ \\
\hline $\mathrm{X}_{2}$ & $5 \mathrm{~A}^{--}$ & $5 \mathrm{~A}^{-}$ & $5 \mathrm{~A}^{-}$ & $5 \mathrm{~A}^{-}$ & $5 \mathrm{~A}^{-}$ & $5 \mathrm{~A}$ & $5 \mathrm{~A}$ & $5 \mathrm{~A}$ & $5 \mathrm{~A}$ \\
\hline $\mathrm{X}_{3}$ & $5 \mathrm{~A}^{-}$ & $5 \mathrm{~A}^{-}$ & $5 \mathrm{~A}^{-}$ & $5 \mathrm{~A}^{-}$ & $5 \mathrm{~A}^{-}$ & $5 \mathrm{~A}^{-}$ & $5 \mathrm{~A}$ & $5 \mathrm{~A}$ & $5 \mathrm{~A}$ \\
\hline $\mathrm{X}_{4}$ & $5 \mathrm{~A}^{-}$ & $5 \mathrm{~A}^{-}$ & $5 \mathrm{~A}^{-}$ & $5 \mathrm{~A}$ & $5 \mathrm{~A}$ & $5 \mathrm{~A}$ & $5 \mathrm{~A}$ & $5 \mathrm{~A}$ & $5 \mathrm{~A}$ \\
\hline $\mathrm{X}_{5}$ & $5 \mathrm{~A}^{-}$ & $5 \mathrm{~A}^{-}$ & $5 \mathrm{~A}$ & $5 \mathrm{~A}$ & $5 \mathrm{~A}$ & $5 \mathrm{~A}$ & $5 \mathrm{~A}$ & $5 \mathrm{~A}$ & $5 \mathrm{~A}$ \\
\hline
\end{tabular}

3.3.2 Comprehensive assessment of landscape quality of target layer

Landscape quality assessment of the target layer takes Nanjing Zijinshan National Forest Park as the assessment object, that is, to assess the overall landscape quality of Nanjing Zijinshan National Forest Park and determine the corresponding landscape quality level. Similarly, the above models (10) - (14) are used to calculate the absolute niche suitability, relative niche suitability and spatial niche suitability of the assessment object. The annual target layer landscape quality is calculated using the weighted average method of the assessment results of the corresponding annual criteria layer index landscape quality. According to the results of the experts' survey, the relative weights of the five indicators in the criteria layer are $0.2568,0.1351,0.1622,0.2162$ and 0.2297 respectively. See Table 9 for specific calculation results of landscape quality of target layer.

Table 9 Comprehensive assessment results of landscape quality of target layer indicators

\begin{tabular}{cccccccccc}
\hline $\begin{array}{c}\text { Assessment } \\
\text { method }\end{array}$ & $\mathbf{2 0 0 0}$ & 2011 & 2012 & 2013 & 2014 & 2015 & 2016 & 2017 & 2018 \\
\hline$\varepsilon_{t \alpha}$ & 0.9386 & 0.9400 & 0.9430 & 0.9434 & 0.9467 & 0.9459 & 0.9477 & 0.9473 & 0.9474 \\
$\gamma_{t \alpha}$ & 0.9262 & 0.9281 & 0.9320 & 0.9364 & 0.9369 & 0.9385 & 0.9346 & 0.9377 & 0.9403 \\
$F_{t \alpha}$ & 0.9342 & 0.9358 & 0.9391 & 0.9410 & 0.9432 & 0.9433 & 0.9431 & 0.9439 & 0.9449 \\
\hline
\end{tabular}

3.3.3 Comparative analysis of landscape quality assessment results

(1) Comparative analysis of the results of landscape quality assessment on the criterion layer. It can be seen from table 7 and table 8 that the overall landscape quality of Nanjing Zijinshan National Forest Park tends to improve, but the speed of improvement is quite slow. In the five indicators of the criteria layer, the quality of forest landscape has a downward trend, mainly due to the increase of buildings in the park and the excessive intensity of tourism, resulting in a certain degree of forest pollution and decline of forest coverage area; the improvement speed of landscape quality of botanical garden is relatively fast, rising from $5 \mathrm{~A}^{--}$to $5 \mathrm{~A}$ in ten years, increasing by two levels; landscape quality and 
comprehensive landscape quality have been improved from $5 \mathrm{~A}^{-}$to $5 \mathrm{~A}$. The highest level of the assessment results of the landscape quality in the criteria layer is $5 \mathrm{~A}$, without a $5 \mathrm{~A}^{+}$, and is far from $5 \mathrm{~A}^{++}$. It can be seen that the existing problems of Nanjing Zijinshan forest park can be obviously found by using the new detailed classification standards. In order to analyze the change range and trend of the annual assessment results of landscape quality of the criteria layer under different methods, the assessment results of the three assessment methods are drawn in the rectangular coordinate system, and the specific results are shown in Figure1.

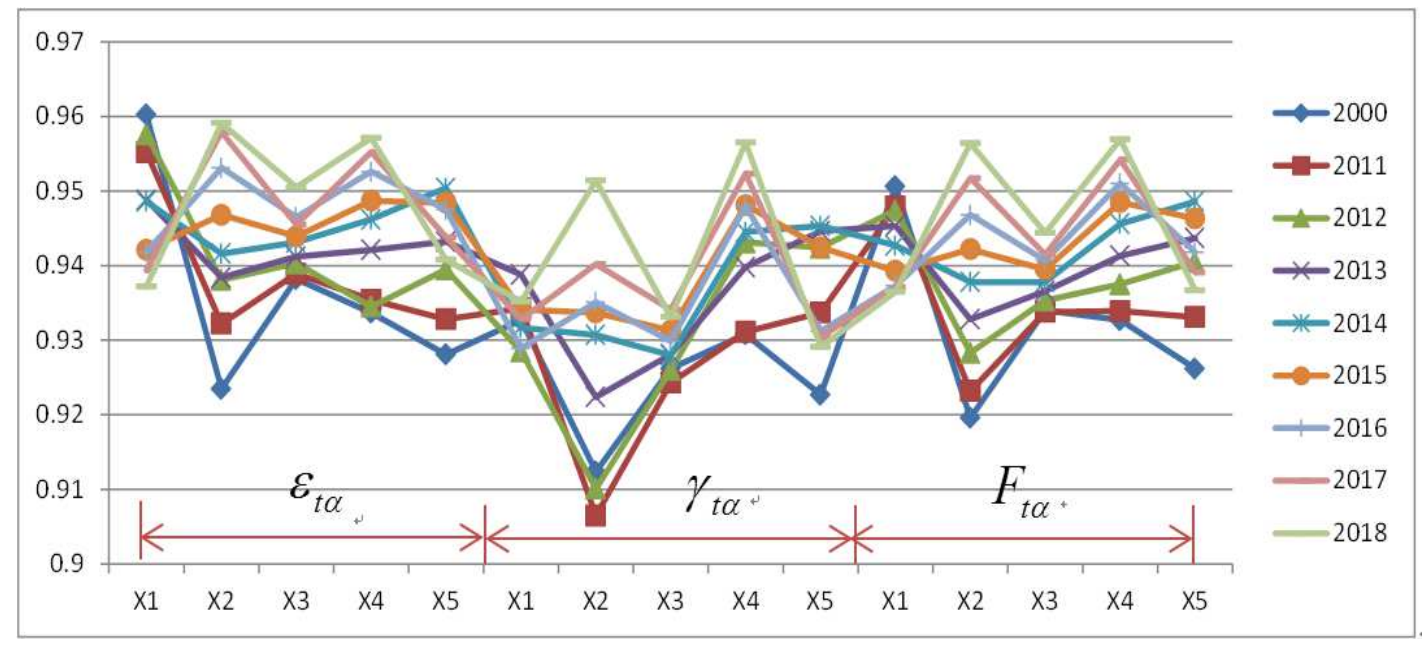

Figure 1 Landscape quality assessment results of standard layer

As can be seen from the above figure, the assessment results of absolute niche suitability model are relatively high, with a medium range of change and a slow downward trend; the assessment results of relative niche suitability model have the largest range of change and the lowest point of the assessment results; the assessment results of spatial niche suitability model are relatively stable, with the smallest range of change and slow upward trend, and are in line with the actual situation of landscape quality of Nanjing Zijinshan National Forest Park. Of the three, spatial niche suitability model is the best to assess the landscape quality of Zijinshan National Forest Park.

(2) Comparative analysis of the assessment results of landscape quality target layer. The target layer indicator is the landscape quality of urban forest parks, which can be calculated by the weighted average method of the assessment results of the criteria layer index or that of the index layer. Under the same assessment model, the calculation results of the two methods are completely consistent. Because three different assessment models are 
used in this paper, it is necessary to select a relatively effective landscape quality assessment model of urban forest parks by comparing the assessment results of the three assessment models. The histogram of the assessment results of the three assessment models is drawn in the rectangular coordinate system, as shown in Figure 2.

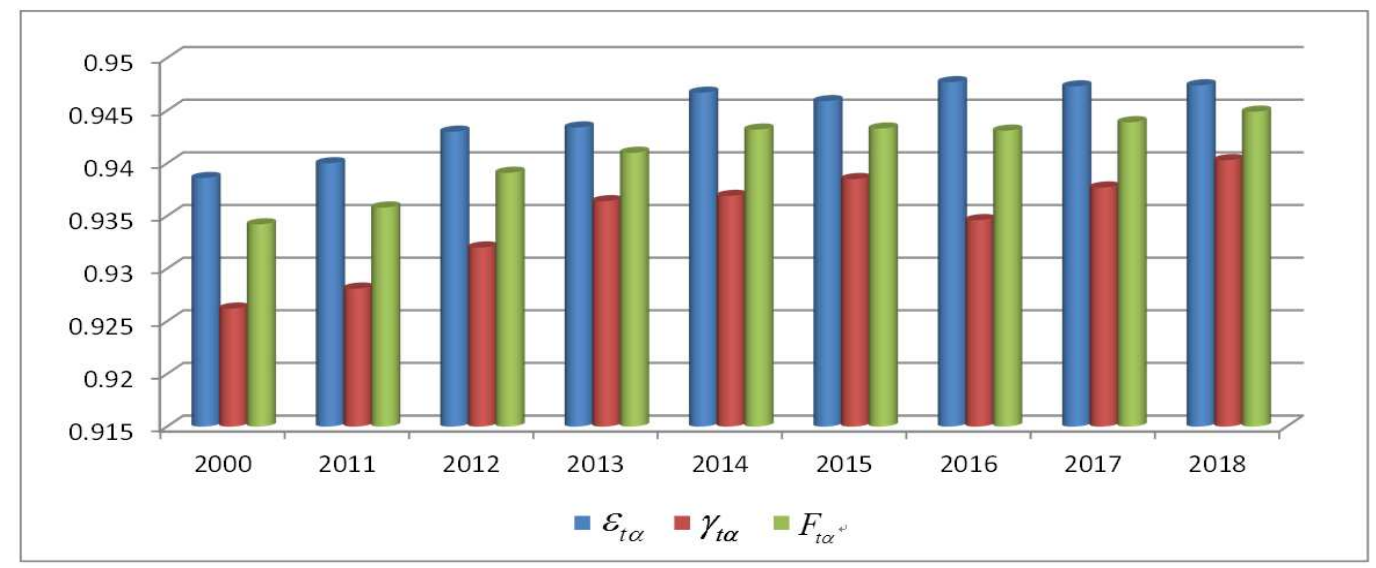

Figure 2 Comparison of assessment results of three models of landscape quality of target layer

It can be seen from Figure 3 that there are great differences among the assessment results of the three assessment models. The assessment results of absolute niche suitability model are relatively high, and this model can improve the landscape quality assessment results of the whole process, especially the initial assessment results which are relatively large and have a relatively large growth range, belonging to the relatively aggressive comprehensive assessment method of landscape quality; the assessment results of relative niche suitability model is contrary to that of absolute niche suitability model. The assessment results of this model have a restraining effect on the initial result, and the process assessment result is not growing fast, which belongs to a relatively conservative comprehensive assessment model of landscape quality. Spatial niche suitability model overcomes shortcomings of the absolute niche suitability model and relative niche suitability model to a certain extent, and absorbs most of the advantages, having the role of improving the initial assessment results, with assessment results of landscape quality growing faster and relatively stable. Assessment results of spatial niche suitability model was compared with the actual landscape quality of Nanjing Zijinshan National Forest Park and proves consistent with the actual situation, and spatial niche suitability model is a better comprehensive assessment method for the landscape quality of urban cultural forest park. 


\section{Discussion}

According to the results of the comprehensive assessment of the landscape quality of Nanjing Zijinshan National Forest Park, we found out some problems in landscape quality management. In order to solve these problems as soon as possible and improve the landscape quality of Nanjing Zijinshan National Forest Park, we discuss these problems based on the actual situation as follows:

\subsection{Downward trend of the forest landscape quality}

According to the statistical report of the government, the forest coverage of Nanjing Zijin Mountain decreased from $81.34 \%$ in 2010 to $70.20 \%$ in 2018 , down $13.6955 \%$, with an average annual decrease of $1.71 \%$; in order to make up for the decline of landscape quality caused by the decline of forest coverage, the management of forest Park adopted such means as increasing investment, repairing scenic spots, strengthening management, etc., so as to make the tree species richness of forest scenic spots. Measures such as improving the value of sightseeing and recreation and increasing the integrity of the landscape have restrained the decline of the quality of the forest landscape. Radar chart is drawn to illustrate the change trend of comparable indexes of the forest landscape quality, and the specific results are shown in Figure 3.

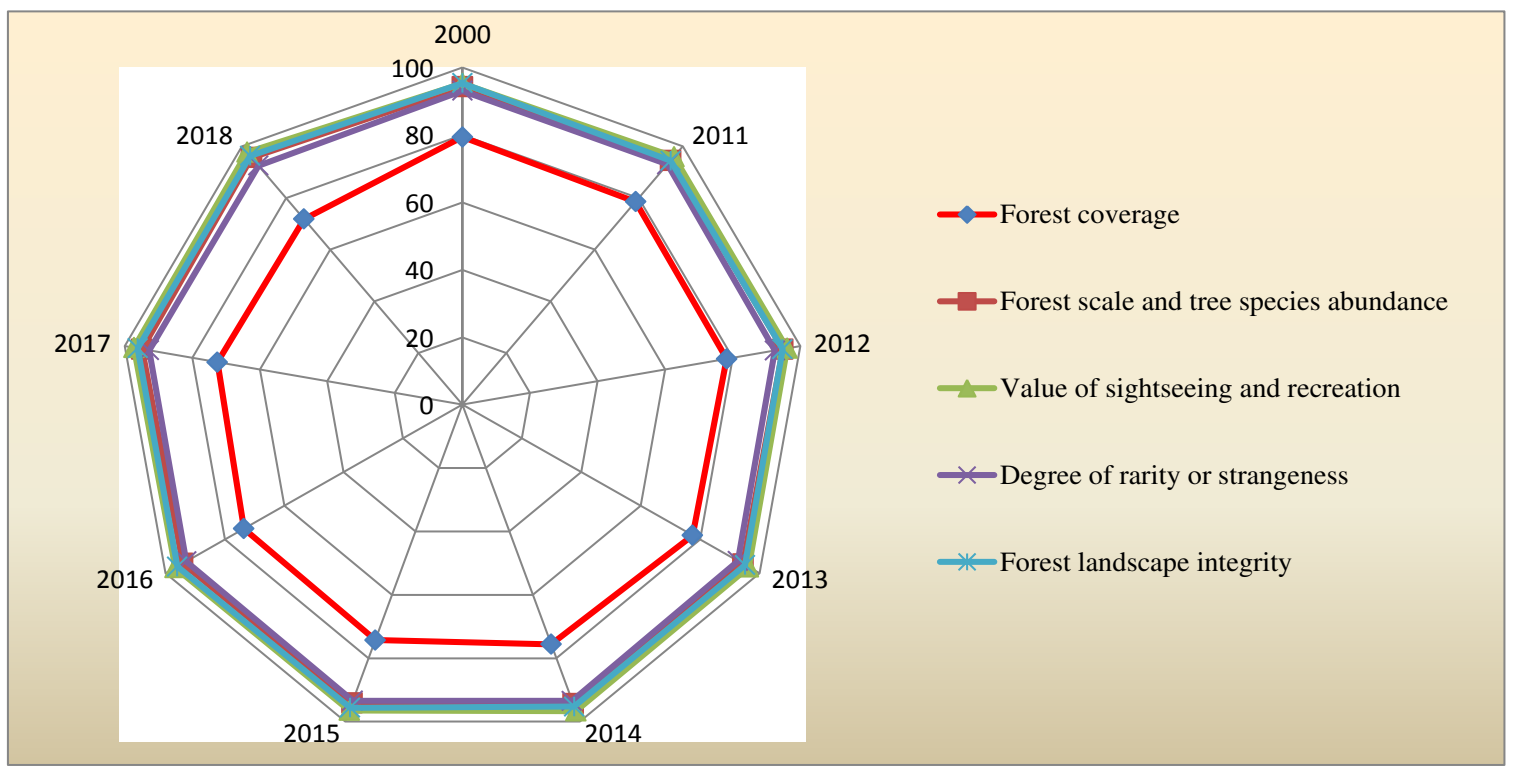

Figure 3 Change trend and relationship of Kobe index of forest landscape quality

4.2 Difficulties in landscape quality improvement of Nanjing Zijinshan National Forest Park 
Based on analysis of the landscape quality assessment results of the criterion layer of Nanjing Zijinshan National Forest Park, in addition to the decline of forest landscape quality, it is indicated that landscape quality of the botanical garden, mountain-water landscape, cultural landscape and comprehensive landscape is difficult to improve. Seen from Table 8, the assessment result grade of landscape quality of Nanjing Zijinshan National Forest Park is $5 \mathrm{~A}^{-}$and $5 \mathrm{~A}$, that is to say, after about a decade of construction, the landscape quality grade of Nanjing Zijinshan National Forest Park has been upgraded from 5A in 2010 to 5A, and has been in the middle level of 5A scenic spot for a long time. Improvement of landscape quality in the construction of characteristic scenic spot is offset by the decrease of forest coverage of the Nanjing Zijinshan National Forest Park. Specifically, forest landscape quality level maintained at 5A level from 2010 to 2014 , and decreased to $5 \mathrm{~A}^{-}$level from 2015 to 2018; landscape quality level of botanical garden is $5 \mathrm{~A}^{--}$level in $2010,5 \mathrm{~A}^{-}$level in 2011-2014 and 5A level in 2015-2018; quality level of landscape remained at 5 $\mathrm{A}^{-}$level from 2010 to 2015, and increased to 5A level from 2016 to 2018; The quality level of cultural landscape is $5 \mathrm{~A}^{-}$level from 2010-2012, and 5A level from 2013-2018; The comprehensive landscape quality is $5 \mathrm{~A}^{-}$level in $2010-2011$ and $5 \mathrm{~A}$ level in $2012-2018$. It is shown that at present the overall landscape quality situation of Nanjing Zijinshan National Forest Parkis lower than the average level of $5 \mathrm{~A}$ level scenic spots, with $5 \mathrm{~A}$ level and a $5 \mathrm{~A}^{-}$level, which should be paid full attention by the administration authorities of Nanjing Zijinshan National Forest Park.

Based on analysis of the landscape quality assessment results of the target layer of Nanjing Zijinshan National Forest Park, there are great differences in the assessment results of the three assessment models, as shown in Figure 3. The assessment result of absolute niche suitability model is relatively high, but in this case, there is no $5 \mathrm{~A}^{+}$ landscape quality level; when relative suitability model is used to assess the landscape quality of the target layer indicators of Nanjing Zijinshan National Forest Park, there is not only no $5 \mathrm{~A}^{-}$level in the assessment result, but also a $5 \mathrm{~A}^{--}$level (see Table 7 for details); In this paper, spatial niche suitability model is chosen, mainly because it is of risk neutral, and more in line with the actual situation of landscape quality assessment of Nanjing Zijinshan 
National Forest Park.

The above analysis can basically prove the conclusion that it is difficult to improve the landscape quality of Nanjing Zijinshan National Forest Park. This shows that the landscape quality management of Nanjing Zijinshan National Forest Park is faced with certain risks. It is important and urgent to take various measures to improve the landscape quality.

\subsection{Landscape quality risk control of spatial niche assessment model}

According to the above assessment results and the analysis, there are differences between landscape quality assessment results of absolute niche suitability model, relative niche suitability model and spatial niche suitability model, which will lead to corresponding landscape quality management risk when working as the basis of landscape quality management. According to the measurement results of different models in Figure 2, absolute niche suitability model is usually a kind of landscape quality assessment method preferred by adventurers, with relatively high assessment results, guiding managers to quickly improve the landscape quality; relative niche suitability model is usually a kind of landscape quality assessment method preferred by conservatives with relatively large assessment results, guiding managers to guard conservatively orientation of landscape quality risk; space niche suitability model, which is risk neutral oriented, advocates to make appropriate decisions on landscape quality management according to the personal ability of the manager, the resources and the environment. Therefore, spatial niche suitability model lays emphasis on landscape quality risk under the premise of ensuring landscape quality.

\section{Conclusions}

In order to study the comprehensive assessment of landscape quality of Nanjing Zijinshan National Forest Park, this paper put forward spatial niche suitability model for the first time. On the basis of literature review, theoretical analysis, questionnaire survey and expert assessment, with the latest research results in China and abroad used for reference, and the actual situation and requirements of landscape quality assessment of Nanjing Zijinshan National Forest Park fully considered, the traditional niche suitability model was improved and 
innovated. Based on absolute niche suitability model and relative suitability model, spatial niche suitability model was constructed by using weighted average method. The three models were applied to the landscape quality assessment of Nanjing Zijinshan National Forest Park, and the assessment results were compared and analyzed. Some problems in the landscape quality management of Nanjing Zijinshan National Forest Park were found out, and deeply analyzed and discussed. The main conclusions are as follows:

First of all, the overall trend of landscape quality of Nanjing Zijinshan National Forest Park is rising, but the difficulty in improving landscape quality is increasing, which is mainly reflected in: the landscape quality assessment results of the criterion layer indicators improved a little in the past decade, and the landscape quality is located below the $5 \mathrm{~A}$ level, with no $5 \mathrm{~A}^{+}$level indicators.

Secondly, the core landscape quality of Nanjing Zijinshan National Forest Park, that is, forest landscape quality shows a downward trend. Although the overall trend of landscape quality of Nanjing Zijinshan National Forest Park is rising, the landscape quality of forest landscape has shown a downward trend, and became $5 \mathrm{~A}^{-}$level from 5A level due to decline of forest coverage and environmental pollution, which indicates potential risks of the landscape quality management.

Finally, the spatial niche suitability model is effective to evaluate the landscape quality of urban forest parks. The spatial niche suitability model combines absolute niche suitability model and relative niche suitability model, taking more influencing factors into account, and overcomes the disadvantages of the traditional niche model to some extent. It is proved through comparative analysis that the assessment results of the spatial niche model are more consistent with the actual situation of the landscape quality of Nanjing Zijinshan National Forest Park.

\section{Abbreviations}

LQ: Landscape Quality; LQA: Landscape Quality Assessment; NSM : Niche Suitability Model; SNSM: Spatial Niche Suitability Model; UFP: Urban Forest Parks.

\section{Acknowledgements}


The research data were provided by Nanjing Statistical Bureau and Nanjing MV Industrial Park Management Committee. This paper is the research result of the Chinese Social Science Foundation Project (19BJL035).

\section{Authors' contributions}

Under the guidance of Professor Sun Tao, this paper was written by Dr. Xiuyan Han and translated into English by Ms. Tianyi Cao. Professor Sun Tao designs the thesis, carries on the model construction, the software computation, the application work and provides the research fund.Ms. Tianyi Cao also participated in the technical processing of research data and related calculations. The results of this paper are innovative and have important theoretical significance and practical value.

\section{Funding}

This work has received funding from the general project of national social science foundation of China: "Research on mechanism and supportive polices of environmental pollution cooperative governance in the process of regional integration development of the Yangtze river delta"(Approval number: 19BJL035).

\section{Availability of data and materials}

The data and materials in this paper are included in the paper and the annex.

\section{Ethics approval and consent to participate}

Not applicable, since the present study is a re-evaluation of existing data.

\section{Consent for publication}

Not applicable

\section{Competing interests}

Professor Tao Sun is employed by Nanjing University of Aeronautics and Astronautics. Xiuyan Han is a doctoral student and Tianyi Cao is a master. This paper is the research result of Professor Tao Sun's project of China Social Science Foundation. Therefore, there is no competitive interest between this article and any person or organization.

\section{Author details}

Authors: Tao Sun (1959-), Men, Born in Taian of Shandong province, Professor and doctoral supervisor of School of Economics and Management, Nanjing University of Aeronautics and Astronautics, Research direction: Environmental Finance; Xiuyan Han (1974-) , Women, Born in Jiamusi of Heilongjiang province, $\mathrm{PhD}$ candidate, College of Economics and Management, Nanjing University of Aeronautics and Astronautics, Senior engineer. Research direction: Energy and environmental management; Tianyi Cao (1998-) , Women, Born in Jiamusi of Heilongjiang province, master degree candidate, School of Economics and Management of Dalian University of Technology. Research direction: Environmental Finance. 


\section{References}

1. Li, Y.; Zhu, S.R.; Chen, Z. H.; Wang X. L. Study on the Perceived Difference of Tourists in Urban Forest Parks: Based on the. Ecological Economy. 2019(1), 114-118.

2. Liu, C.; Xu, N.; Song, J. D.; Hu, S.C. Research on visitors' thermal sensation and space choices in an urban forest park. Acta Ecologica Sinica. 2017, 37(10), 3561-3569.

3. Laetitia,T.The recreational services value of the nearby periurban forest versus the regional forest environment. Journal of Forest Economics. 2017, 28, 33-41.

4. Lisa, H.; Katharina, P; Corinna, B.; Thomas, F. Effects of habitat and landscape quality on amphibian assemblages of urban storm water ponds. Urban Ecosystems. 2017, Vol.20 (6), pp.1249-1259.

5. Liu, T.T.; Kong, Y.; Wu, Y; Zhu, L.Y.; Zhang, D.H. Provincial forest ecological security assessment in China based on the entropy weight of the fuzzy matter-element model. Act EcologicaSinica. 2017, 37(15), 4946-4954.

6. Feng, L.; Zhao, J. Research on Landscape Quality Assessment of Urban Parks Based on AHP-TOPSIS Combination Model. Journal of Shandong Agricultural University (Natural Science Edition). 2018, 49(5), 777-781.

7. Yujia, Z.; Perver, K.B.; Wu, C.H. Spatial distributions and use patterns of user groups in urban forest parks: An examination utilizing GPS tracker. Urban Forestry \& Urban Greening.2018, 35, 32-44.

8. Wang, C.; Zhai, M.P.; Jin, Y.S.; Ma, R.G. Current Research and Prospect son Forest Landscape Quality Assessment. World Forestry Research.2006, 19(6), 18-22.

9. Peng, W.H.; Liu, W.Q.; Cai, W.B.; Wang, Xin.; Huang, Z.; Wu, C.Z. Assessment of ecosystem cultural services of urban protected areas based on public participation GIS (PPGIS) : A case study of GongqingForestParkinShanghai,China.ChineseJournalofApplied Ecology, Feb. 2019, 30(2):439-448.

10. Mizuuchi, Y.; Nojima, T.; Furuya, K. A Study on Landscape Assessment by Forest Trail Visitors in a Nature Park: A Case of Meiji no Mori Takao Quasi-National Park. 2016, 9:91-102.

11. Han, Y.W.; Kang.W.M.; James, T.; Song, Y.K. Modeling the effects of landscape patterns of current forests on the habitat quality of historical remnants in a highly urbanized area. Urban Forestry \& Urban Greening, 2019, 41, 354-363.

12. Yamina, M.R.; Pablo, L.P.; María, V.L.; Guillermo, M.P. Potential biodiversity map of understory plants for Nothofagus forests in Southern Patagonia: Analyses of landscape, ecological niche and conservation values. Science of The Total Environment. 2019,682,301-309.

13. Göran, B.; Astrid, Z.; Hans, E. Planning on a wider scale-Swedish forest owners' preferences for landscape policy attributes. Forest Policy and Economics.2019, 104,170-181.

14. Erkki, M.; Artti, J.; Liisa,T.; Jouni, K.; Mikko, K. Participation and compensation claims in voluntary forest landscape conservation: The case of the Ruka-Kuusamo tourism area, Finland. Journal of Forest Economics, 2018, 33, 14-24.

15. Cibele,B.; André,A. N.; Ricardo,P.R.; Renata, P. Harvestmen in an Atlantic forest fragmented landscape:Evaluating assemblage response to habitat quality and quantity. Biological Conservation.2007, 139(3-4), 389-400. 
16. Makoto, S.; Asako, M.; Naoyuki, F.; Kazuhiko, K. Using landscape metrics and topographic analysis to examine forest management in a mixed forest, Hokkaido, Japan: Guidelines for management interventions and assessment of cover changes. Forest Ecology and Management.2009, 257(4), 1208-1218.

17. Zheng, Y.; Lan, S.E.; Chen, Y.W.; Chen, X.Y.; Jianwen, D. Visual sensitivity versus ecological sensitivity: An application of GIS in urban forest park planning. Urban Forestry \& Urban Greening. 2019,41,139-149.

18. Li, Q.S.; Huang,J.L.; Wang,C.; Lin,H.S.; Zhang, J.W.; Jiang, J.L.; Wang,B.K. Land Development Suitability Assessment of Pingtan Island Based on Scenario Analysis and Landscape Ecological Quality Assessment. Sustainability 2017, 9(7), 1292. Doi: 10.3390/su9071292.

19. Athanasios, A. G.; Cristiana, M.C.; Mihai, R.N.; Diana, A.O.; Irina, I.N. Urban Landscape Quality Index-Planning Tool for Evaluating Urban Landscapes and Improving the Quality of Life. Procedia Environmental Sciences.2016, 32, 155-167.

20. Xuesong, X.; Jianyu, K.; Wenhu, H.; Yun, S. The Trend of landscape planning as shown through publications in the Journal of Landscape and Urban Planning during the past twenty years. Acta Sci. Nat. Univ. Pekin. 2008, 44, 651-660.

21. Shearer, K.S.; Xiang, W.N. Representing multiple voices in landscape planning: A land suitability assessment study for a park land-banking program in Concord, North Carolina, USA. Landsc. Urban Plan. 2009, 93, 111-122.

22. David, C. P.; Hugh, P.P.; Anne, W.G. Integrating life history traits and forest structure to evaluate the vulnerability of rainforest birds along gradients of deforestation and fragmentation in eastern Australia. Biological Conservation.2015,188, 89-99.

23. Poudyal,N. C.; Hepinstall-Cymerman, J.; Gaither,C. J.; Boley, B.B. Exploring the role of forest resources in reducing community vulnerability to the heat effects of climate change. Forest Policy and Economics, 2016, 71, 94-102.

24. Fischer, A.P. Forest landscapes as social-ecological systems and implications for management. Landsc. Urban Plan. 2018, $177,138-147$.

25. Pierskalla, C.D.; Saunders, K.E.; McGill, D.W.; Smaldone, D.A. Forest landscape assessment: The effects of pre-experience education on public perception of scenic beauty. In Proceedings of the 2007 Northeastern Recreation Research Symposium, Bolton Landing, NY, USA, 15-17 April 2007.

26. Felipe, R.P.; Pedro, G.; Silvio Frosini de Barros F.; Seth, J. W. Multi-scale assessment of forest cover in an agricultural landscape of Southeastern Brazil: Implications for management and conservation of stream habitat and water quality. Ecological Indicators.2018, 85, 1181-1191.

27. Yuko, T.; Juyoung, L.; Bum-Jin, P.; Liisa, T.; Yoshifumi, M. Physiological and psychological effects of viewing urban forest landscapes assessed by multiple measurements. Landscape and Urban Planning. 2013,113,90-93.

28. Cheng, L.; Ge, S.; Zhifeng, W.; Honglin, Z.; Jiong, C.Soil physiochemical properties and landscape patterns control trace metal contamination at the urban-rural interface in southern China. Environmental Pollution.2019, 250,537-545.

29. Jiangzhou, W.; Yongde, Z.; Jinyang, D.Assessing and Mapping Forest Landscape Quality in China. Forests 2019, 10(8), 684; https://doi.org/10.3390/f10080684.

30. Wang, N.; Zhong, Y.D.; Li, S. SBE Based Assessment of In-forest Landscape Aesthetic Quality of Forest Park in Suburb. Journal of Northwest Forestry University. 2017, 32(1), 308-414. 
31. Cheng, Y.R.; Zhang, X.P. Microclimate's Affection on the Composition of Plant Community on Southern and Northern Slope of Purple Mountain.Journal of Anhui Normal University (Natural Science).2012,35(1),44-48.

32. Li, M.Y.; Cheng, Y.; Xu, T.; Jiang, W.Q. Multi-Cultural Characteristics and Multi-Functional Management Countermeasures of Zijin Mountain National Forest Park. Journal of Beijing Forestry University (Social Sciences). 2012, $11(4), 49-54$.

33. Hu, X.M.; Cheng, N.Y. Change Characteristics of Negative Oxygen Ions in Urban Forest Parks and the Leisure and Health Care Function Based on Data Analysis of Purple Mountain National Forest Park. Business \& Economy. 2016,(04),73-75.

34. Wang, Z.; Li, M.Y. Methods of Color Plan of Landscape Forest at All Seasons—a Case Study of Purple Mountain. Forest Resources Management .2017,(S1),70-76 DOI:10.13466/j.cnki.lyzygl.2017.S0.012.

35. Zhou, L.; Xiao, P.; Tang, S.; Chen, L.L. Study on Urban Forest Recreationists' Satisfaction Based on Perceived Value: A Case in Purple Mountain National Forest Park, Nanjing. Ecological Economy. 2014, 30(05), 146-152.

36. Yan, W.J.; Kong, F.; Yin, H.W.; Sun, C.F.; Xu, F.; Li, W.C.; Zhang Xiaotian. Analysis of factors contributing to the cooling effects of Purple Mountain Forest Park. ActaEcologica Sinica.2014, 34(12), 3169-3178. DOI: 10.5846/stxb201310302625.

37. Yang, C.G.; Guo, J.Y. Tourism Interpretation of Urban Forest Park under the Background of the Construction of Ecological Civilization-A Case Study of Nanjing Zijin Mountain Forest Park. Journal of Northwest Forestry University. 2014, 29(03), 221-226 DOI:10.3969/j.issn.1001-7461.2014.03.44.

38. Xu, H.B.; Ju, F.; Liu, S.W.; Wan, Z.Z. Plant diversity and its conservation strategies in Zijin Mountain National Forest Park in Nanjing. Journal of Jiangsu Forestry Science \& Technology. 2011(1),30-35.

39. Baolong, H.; Rusong, W.; Yu, T.; Hui, G. Urban population agglomeration in view of complex ecological niche: A case study on Chinese prefecture cities. Ecological Indicators.2014, 47,128-136.

40. Dong, B.; Chen, L.P.; Qian, G.Y. Synthetic Assessment of Ecological Suitability of Forest Mathematics Model Based on Remote Sensing Data. Journal of Natural Resources.2011,26(3),468-475.

41. Laura, J.; Jorge, S.; Christen,J. A.; Desireé, S. On the problem of modeling a fundamental niche from occurrence data. Ecological Modelling.2019, 397, 74-83.

42. Marinez Ferreira de Siqueira, GiseldaDurigan, Paulo de Marco Júnior, A. Townsend Peterson. Something from nothing: Using landscape similarity and ecological niche modeling to find rare plant species.Journal for Nature Conservation.2009, $17(1), 25-32$.

43. Qin Li-li, WANG Dao-ping, ZHOU Chao. Sustainability assessment of regional innovation system based on synthetic niche-fitness. Systems Engineering-Theory\&Practice, 2011, 31(5), 927-935.

44. Wang, W.; Nian, P.H.; Zhu, D.T.; Zhang, W.X. Analysis of regional multifunction assessment and evolution based on niche breadth model-Taking Beijing as an example. World Regional Studies.2016, 25 (6), 66-77. 
Figures

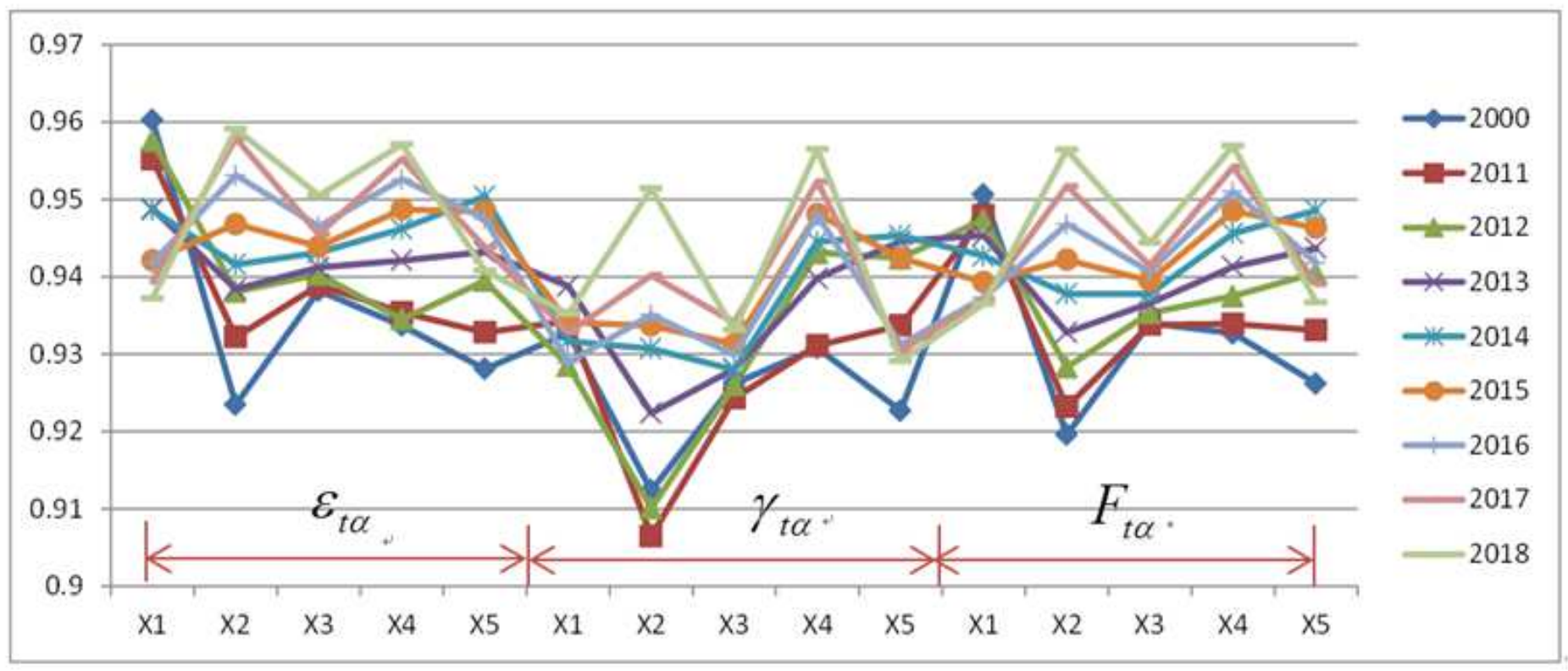

Figure 1

Landscape quality assessment results of standard layer

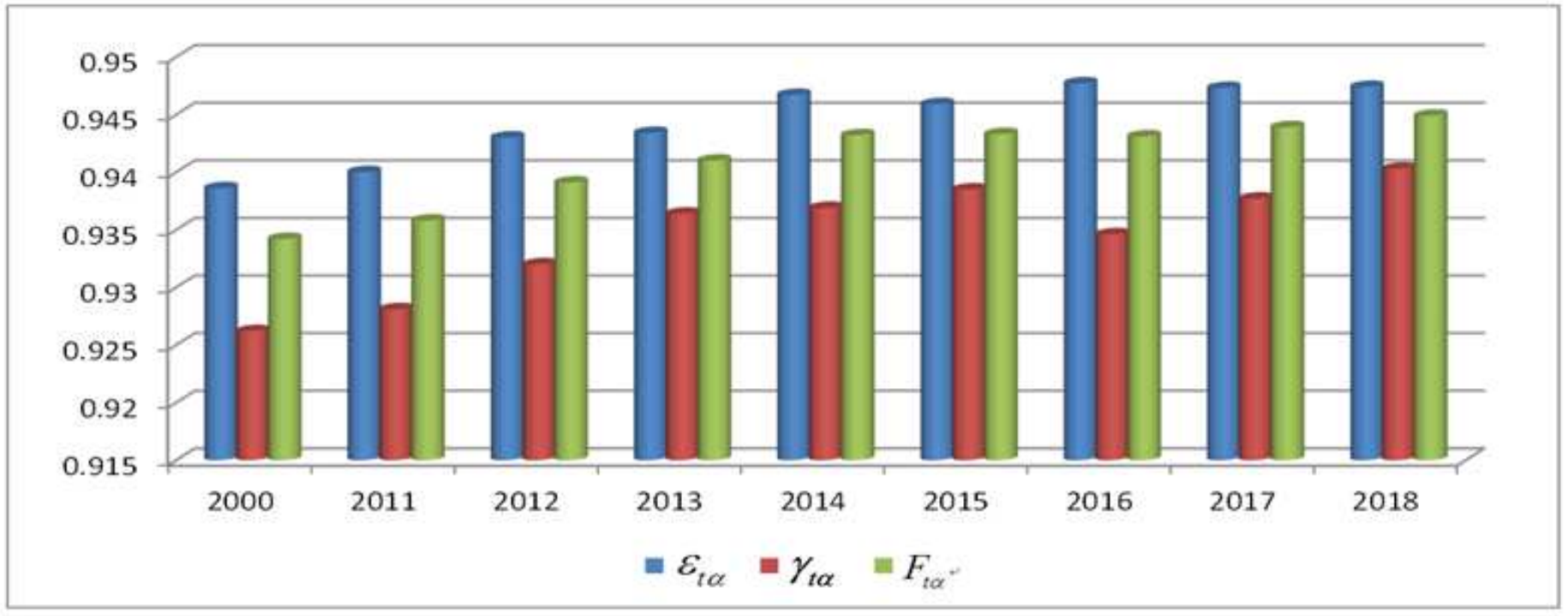

Figure 2

Comparison of assessment results of three models of landscape quality of target layer 


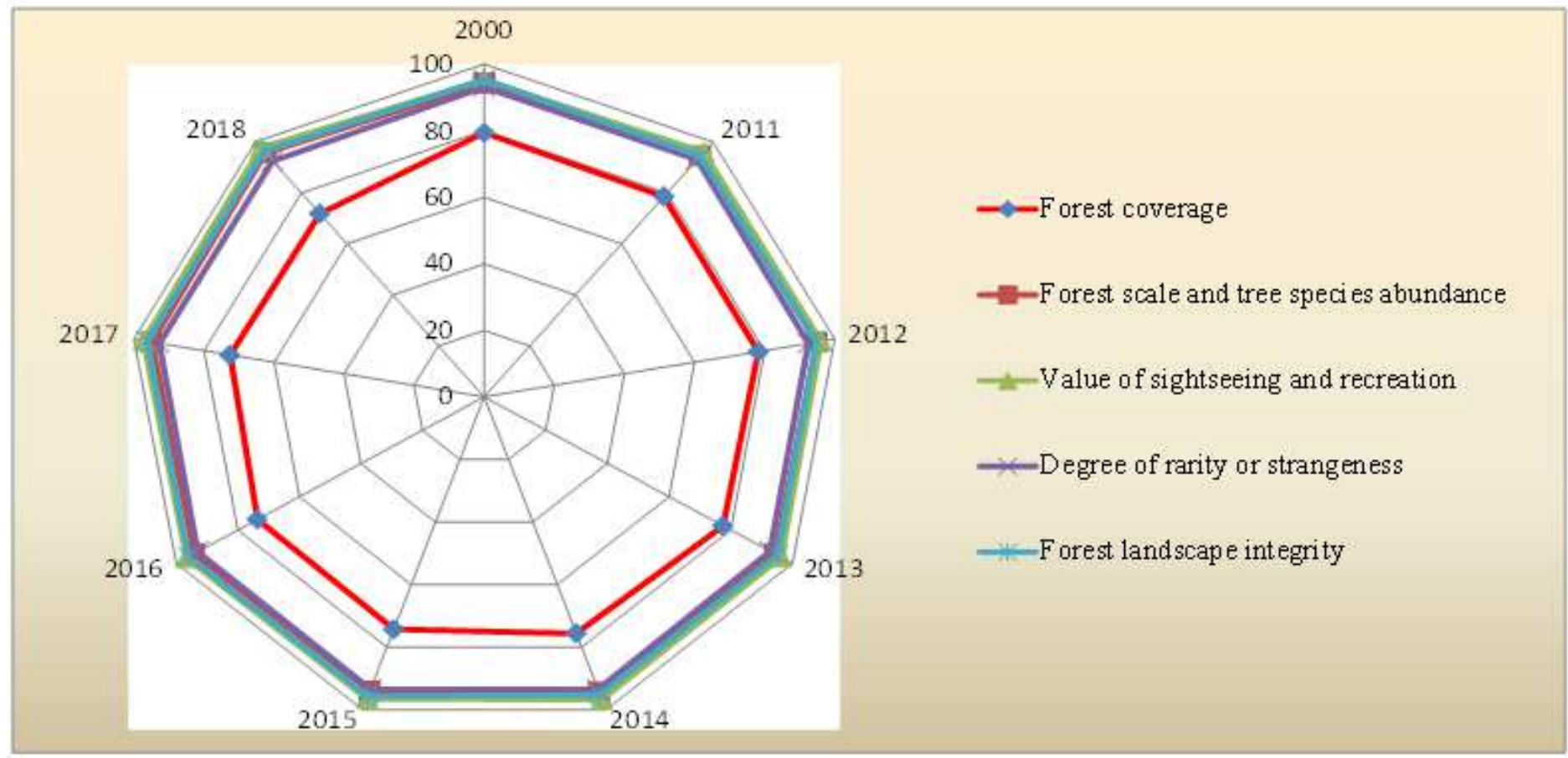

\section{Figure 3}

Change trend and relationship of Kobe index of forest landscape quality

\section{Supplementary Files}

This is a list of supplementary files associated with this preprint. Click to download.

- Highlights.pdf

- GraphicalAbstract.pdf 